\title{
Multi-Contracting Mechanism Design ${ }^{1}$ \\ David Martimort
}

\begin{abstract}
Multi-contracting practices prevail in many organizations be they public (governments) or private (markets). This article surveys the literature on common agency, a major example of such multi-contracting settings. I first highlight some specific features of common agency games that distinguish them from centralized contracting. Then, I review the tools needed to describe allocations which are implementable as common agency equilibria. Economic examples are used to characterize equilibria under both complete and asymmetric information. Particular focus is put on the multiplicity problem and the (interim) efficiency properties of those equilibria. The comparison of those equilibria with the outcomes achieved under centralized contracting allows us to assess the transaction costs of multi-contracting. I also argue that, in some specific contexts, common agency may implement the optimal outcome that would be achieved under centralized contracting if collusion between agents were an issue. More generally, common agency might outperform centralized contracting when either collusion or limited commitment matters.
\end{abstract}

Keywords: Multi-Principals, Common Agency, Mechanism Design, Transaction Costs.

\section{Introduction}

Incentive Theory is by now a mature field that has deeply changed our view of organizations and markets over the last thirty years or so. In the conceptual framework proposed early on by Hurwicz (1972) and largely inspired by the planification literature, the whole economy is ruled by a single (or complete) grand-contract. Within this framework, decentralized information and strategic behavior by informed agents at the periphery of the organization can easily be handled by means of simple incentive constraints that fully describe the set of feasible allocations available under asymmetric information. Once equipped with the Revelation Principle, ${ }^{2}$ modelers are able to describe the feasible set

\footnotetext{
${ }^{1}$ I benefitted of many discussions on the topic of this lecture and on related issues with several coauthors, among which Antoine Faure-Grimaud, Marc Ivaldi, Fahad Khalil, and Humberto Moreira. Special thanks of course to Lars Stole whose collaboration has shaped much of my views on multi-contracting mechanism design. Vianney Dequiedt, Denis Gromb, Jérôme Pouyet, Wilfried Sand-Zantman and Aggey Semenov kindly provided comments on an earlier version. I was lucky to discuss many of the ideas developed below with Jean-Jacques Laffont. Many thanks to Thomas Palfrey for his useful discussion at the 2005 World Congress of the Econometric Society and to Torsten Persson for his comments.

${ }^{2}$ Gibbard (1973), Green and Laffont (1977), Dasgupta, Hammond and Maskin (1978) and Myerson (1979).
} 
and assess the performance of an organization with a given objective function. The analysis can then proceed to determine the properties of the optimal contract chosen by a planner running this organization. Finally, one may also investigate the mechanisms that can be used to implement this outcome in practice.

This modelling framework is useful to understand how simple organizations and markets evolve in isolation from any external influence. Economists agree to recognize that a convenient set of modelling tools and theorems is now available to describe the simple contractual relationship between a buyer and a seller or between a regulator and regulated firms. We are also confident that the theory of auctions is a well-established body of literature which explains in details one of the most basic resource allocation problem.

Despite these successes, Incentive Theory has repeatedly being subject to criticisms coming from various horizons. The first line of criticisms is external to the field and can be best summarized by the view held by some sociologists who argue that Incentive "Theory assumes that social life is [only] a serie of contracts". ${ }^{3}$ In my view, the discomfort of other social scientists towards Incentive Theory stems in part from the fact that it most often either focuses on the microeconomic bilateral relationship within a single principal-agent pair taken in isolation or, at the other extreme, it embraces the whole economy within a single grand-contract. By taking these two polar views, Incentive Theory fails to provide an intermediate perspective on the interactions between organizations and markets which are the focus of organizational theorists coming from other fields of social sciences.

The second line of criticisms is internal to economic theory. It comes from our skepticism towards the grand-contracting approach which puts excessive emphasis on the completeness of the contract. Indeed, one of the most basic assumptions underlying the Revelation Principle is what Palfrey (1992) coined as the control assumption. This assumption stipulates that the planner can control all communications that agents of the organization can undertake. When such control is not feasible, the economy can no longer be ruled by a single mechanism but by complex interactions among multiple mechanism designers. In this context, contracts are necessarily incomplete in the sense that they cannot prevent an agent from contracting with other principals. Any departure from the outcome that could have been achieved under centralized contracting can then be associated to this incompleteness. The difference between the outcomes with and without centralized contracting gives us a measure of the corresponding transaction costs.

\footnotetext{
${ }^{3}$ This is a quote from one of the leading organizational theorists, Perrow (1986, Chapter 7, p. 224).
} 
Such analysis is a first step towards some comparative analysis showing how different contractual and organizational forms might reduce those transaction costs.

This survey covers a body of literature which has studied interactions among mechanism designers with an emphasis on common agency, a major example of multi-contracting. Under common agency, several principals contract with a common agent to influence his decision-making. This setting is relevant to discuss the organization of the firm as a nexus of contracts linking its management with various stakeholders be they shareholders, lenders, regulators, customers and suppliers. It also helps understanding the organization of the government as a collection of legislative committees, bureaus and regulatory agencies which do not necessarily cooperate. Section 2 provides more examples.

Ideally, a complete survey of multi-contracting should also cover hierarchical contracting, competition between hierarchies and collusion within organizations. Space constraints mean that I will only incidentally touch on those issues in passing. I will also focus on adverse selection and put aside moral hazard issues despite their importance. Nevertheless, common agency already offers a nice overview of some of the theoretical inquiries that the analysis of multi-contracting environments requires. Those inquiries can be classified as follows.

- On the positive side, one can take as given the existence of multi-contracting structures ${ }^{4}$ and ask the following questions. What is the set of mechanisms available to competing principals? Which allocations are implementable as contract equilibria? How much welfare is lost absent centralized contracting? Do we get a measure of the transaction costs associated with multi-contracting?

- In a more normative perspective, and given that multi-contracting prevails both within and across organizations, one may look for some rationale behind those structures. Since centralized contracting internalizes the contractual externalities that arise under multicontracting, the difficulty consists then in proving the latter's optimality or, at least, its good performances in specific contractual environments which are necessarily constrained in some way to limit the benefits of centralized contracting.

Much of the research in the field has focused on the first issues. These efforts are covered in Sections 3 to 5 below. Much less effort has been devoted to the more normative

\footnotetext{
${ }^{4}$ For instance, competing regulatory agencies may receive their mandates at different points in time or from different governments and the allocation of powers among them is a consequence of either history or geography. Anti-trust policies may also preclude centralized contracting between competing retailers and their common manufacturer.
} 
issues which are addressed in Section 6. Section 7 briefly concludes and proposes alleys for further research.

\section{Examples and Modelling Issues}

I shall start by presenting a few examples of common agency models. In any such model, several principals $P_{i}(i \in\{1, \ldots, n\})$ want to influence a decision taken on their behalf by a common agent $A$. My goal here is to briefly highlight some of the basic issues arising in such modelling.

- Example 1: Regulation. Consider the regulation of a public utility by $n$ distinct regulators (principals). For instance, one agency may be an economic regulator concerned by consumers' surplus. Another one may be an environmental regulator controlling pollution. Regulators have specific objective functions given by

$$
V_{i}=S_{i}(q)-t_{i}, \quad i \in\{1, \ldots, n\}
$$

where $q$ is the firm's output. This output may be multidimensional and of the form $q=\left(q_{1}, \ldots, q_{n}\right)$ where $q_{i}$ might itself be an array of activities controlled by regulator $P_{i}$. The surplus function $S_{i}(\cdot)$ is strictly concave in $q$, and captures the (algebraic) benefit of the firm's activity from regulator $P_{i}$ 's point of view. $t_{i}$ is a regulatory transfer paid to the firm by $P_{i}$. The firm's profit can be written as:

$$
U=\sum_{i=1}^{n} t_{i}-\theta C(q)
$$

where $C(q)$ is a cost function, which is increasing and convex. The efficiency parameter $\theta$ is drawn from a cumulative distribution $F(\cdot)$ on the interval $\Theta=[\underline{\theta}, \bar{\theta}]$ with an atomless and everywhere positive density $f(\cdot)$. Depending on the informational environment under scrutiny, the parameter $\theta$ might either be private information for the firm or not. This information structure is common knowledge.

The reader familiar with the regulation literature will have recognized an extension of the framework developed by Baron and Myerson (1982). The only difference is the fragmented nature of regulatory control which is shared among several government units. I will be silent on the definition of social welfare underlying the regulators' objectives. Social welfare might be defined as the sum of these objectives if regulators have clear and 
separable objectives. However, regulatory agencies could also have overlapping missions. ${ }^{5}$ In any case, it is useful to consider an hypothetical setting where all principals are merged into a single entity with the objective function $\sum_{i=1}^{n} V_{i}$.

Under complete information, efficiency requires to maximize the joint-payoff of the grand-coalition made of all principals and the agent. The first-best output $q^{*}(\theta)$ satisfies:

$$
\sum_{i=1}^{n} S_{i}^{\prime}\left(q^{*}(\theta)\right)=\theta C^{\prime}\left(q^{*}(\theta)\right)
$$

For future references, it is also useful to describe the cooperative solution achieved under asymmetric information had all principals merged as one. The techniques to derive this second-best (or interim efficient in the sense of Holmström and Myerson (1983)) solution are by now standard. ${ }^{6}$ The cooperative outcome $q^{C}(\theta)$ satisfies:

$$
\sum_{i=1}^{n} S_{i}^{\prime}\left(q^{C}(\theta)\right)=\left(\theta+\frac{F(\theta)}{f(\theta)}\right) C^{\prime}\left(q^{C}(\theta)\right) .
$$

Under asymmetric information, the efficiency parameter $\theta$ is replaced by a virtual efficiency parameter $\theta+\frac{F(\theta)}{f(\theta)}$ that takes into account the fact that the agent's information rent is costly from the merged entity's viewpoint.

- Example 2: Lobbying. Several lobbying groups (principals) want to influence a decision-maker (the common agent) who chooses the level of a public good or, more generally, a policy variable (a regulated price, an import tariff, or a number of permits). These principals non-cooperatively offer contributions to influence the agent's choice. Their objective functions are given by (1). The agent's utility function is again as in (2) where $C(q)$ should now be viewed as the opportunity cost of choosing a quantity $q$ of public good. ${ }^{7}$ Contrary to Example 1 where regulatory contracts are mandatory, the agent can now reject a subset of the contributions.

- Example 3: Vertical Contracting. Two competing retailers $P_{1}$ and $P_{2}$ (the principals) compete on a final market. They produce the final good with a one-to-one Leontieff technology using a common input produced by a manufacturer (the common agent). The agent's reservation payoff is, for simplicity, normalized to zero. The retailers' and manufacturer's profit functions are respectively given by:

$$
V_{i}=P\left(q_{i}+q_{-i}\right) q_{i}-t_{i}, \quad i=1,2, \text { and } U=t_{1}+t_{2}-\theta C\left(q_{1}+q_{2}\right)
$$

\footnotetext{
${ }^{5}$ An extreme case would be when social welfare maximization is replicated among the different agencies. Then, we have $S_{1}(\cdot)=\ldots=S_{n}(\cdot)$.

${ }^{6}$ See Laffont and Martimort (2002, Chapter 3) for instance.

${ }^{7}$ This may include the welfare of unorganized groups which are not active lobbyists.
} 
where the inverse demand function satisfies $P^{\prime}<0$ and $P^{\prime \prime} \leq 0$, and the manufacturer's cost function is again increasing and strictly convex $\left(C^{\prime}>0, C^{\prime \prime}>0\right)$. The manufacturer may either accept both offers, none or only one.

An efficient outcome maximizes now the profit of the vertically and horizontally integrated structure. The (symmetric) efficient production vector $q^{*}(\theta)=q_{1}^{*}(\theta)=q_{2}^{*}(\theta)$ is the monopoly outcome defined as:

$$
2 P^{\prime}\left(2 q^{*}(\theta)\right) q^{*}(\theta)+P\left(2 q^{*}(\theta)\right)=\theta C^{\prime}\left(2 q^{*}(\theta)\right) .
$$

A Few Issues: In all those examples, inefficient contractual outcomes may arise because of some underlying frictions in contracting. Those frictions may be due to arbitrary restrictions of the space of contracts. They may also stem from asymmetric information and the associated screening costs incurred by the principals in such contexts. A major difficulty of the common agency literature is precisely to understand the new frictions, if any, which are due to the principals' non-cooperative behavior. This analysis requires a careful study of the contracting possibilities available to the principals. Different contracting possibilities may either alleviate or exacerbate frictions depending on the context. When looking at those contracting possibilities, common agency introduces some new features that are not present under centralized contracting and that need to be carefully studied:

- Under centralized contracting, the agent has no other option than refusing the contract offered by the merged entity. This participation decision is most often modelled by introducing an exogenously given reservation payoff for the agent. Under common agency, the agent may either be forced to accept all contracts at once or may be able to play some principals against others by threatening to accept only a subset of the offers he receives. We will talk about intrinsic common agency in the former case and delegated common agency in the latter. ${ }^{8}$ Intrinsic common agency arises in Example 1. Delegated common agency occurs instead in Examples 2 and 3.

- Examples 1 and 3 also highlight another important feature of common agency. As we split control among different principals, we might also change the information available to those principals. In Example 1, an economic regulator may observe the firm's output whereas an environmental regulator has expertise to observe polluting emissions. In Example 2 , retailer $P_{1}$ may not be able to observe and verify the amount of input sold by the manufacturer to retailer $P_{2}$. In the case of public agency, both principals may still be

\footnotetext{
${ }^{8}$ Bernheim and Whinston (1986a) coined these expressions.
} 
able to contract on the whole output vector $q=\left(q_{1}, q_{2}\right)$. Public agency always occurs in Example 2 but also in Example 3 if, for instance, both retailers can observe and verify the price at which the good is sold on the final market. Instead, in the case of private agency, output $q_{i}$ is observed and verified only by $P_{i}$ and the contract that this principal offers to the agent can only use this variable as a screening instrument. Still in Example 3, private agency occurs when retailers offer specific non-verifiable services which are included in the price package to their customers. As we move from public to private agencies, we limit the principals' contracting possibilities and may change the equilibrium sets of the common agency game.

Whether we have delegated/intrinsic, public/private and symmetric/asymmetric information offers a large panels of game forms which are all relevant in specific applications. Each of those games requires careful study. Nevertheless, I shall try to highlight below a few common themes of the literature.

Contract Spaces and Incompleteness: An important preliminary step is to define the contract spaces available to the principals. Before doing so, it is useful to think of an interesting class of contracts, nonlinear prices, which are often observed in practice and to see how they relate to the degree of incompleteness of the contracts:

- Under public agency, principals may offer nonlinear prices of the form $t_{i}(q)$ and let the agent choose the publicly observable output $q$. The only source of contractual incompleteness is the lack of centralized contracting. ${ }^{9}$

- Under private agency, principals can only offer nonlinear prices which link the agent's payment to the available observable, typically of the form $t_{i}\left(q_{i}\right)$. The agent still chooses the output $q=\left(q_{1}, q_{2}\right)$. Contracts are thus more incomplete. Not only principals do not cooperate in contracting but they also contract on different variables.

Taxation and Revelation Principles: Under centralized contracting, the Revelation Principle characterizes the set of incentive-feasible allocations. This description in terms of direct and truthful mechanisms is quite tractable and amenable to a simple set of incentive constraints. Characterizing the set of implementable allocations is a crucial step of the analysis before proceeding to optimization once the organization's objective function has been defined. Unfortunately, for multi-contracting environments, the applicability of the Revelation Principle comes into question.

\footnotetext{
${ }^{9}$ Under delegated common agency, principals could also make discriminatory offers and link the agent's compensation to whether he accepts other principals' contracts or not.
} 
Under multi-contracting, one may be interested in analyzing the set $P B E\left(\Gamma_{\mathcal{M}_{1} \times \ldots \times \mathcal{M}_{n}}\right)$ of the perfect Bayesian equilibria of a common agency game $\Gamma_{\mathcal{M}_{1} \times \ldots \times \mathcal{M}_{n}}$ obtained when each principal offers mechanisms using an arbitrary communication space $\mathcal{M}_{i}$ with the agent. A (trivial and somewhat abusive) version of the Revelation Principle would consist in replacing every communication space $\mathcal{M}_{i}$ by the set of types $\Theta$ so that any equilibrium $\sigma^{*}$ in $P B E\left(\Gamma_{\mathcal{M}_{1} \times \ldots \times \mathcal{M}_{2}}\right)$ yields payoffs which can be replicated by an equilibrium $\tilde{\sigma}^{*}$ in $\operatorname{PBE}\left(\Gamma_{\Theta^{n}}\right)$ with truthtelling as a strategy profile for the agent in his relationship with each principal. This naive approach fails on three fronts:

- Principals may have used the agent as a pure correlating device when the communication spaces $\mathcal{M}_{i}$ are used. By restricting the agent to a truthful strategy vis-à-vis each principal, one may lose the possibility of correlating behavior. This difficulty can nevertheless be fixed by appending to the agent's type a public correlating device.

- Even when direct mechanisms are used, the agent may be mixing among messages as part of the equilibrium behavior. ${ }^{10}$

- Out of equilibrium messages available with indirect mechanisms may play a significant role in preventing deviations. One can sustain equilibrium outcomes with indirect mechanisms which would not survive with direct revelation mechanisms. Conversely, focusing on direct mechanisms may also introduce equilibria which would not hold if deviations to a larger space of mechanisms were available to the principals. These difficulties are prevalent in economic applications as I will show below.

These shortcomings mean that new tools are needed to characterize equilibrium outcomes. Two paths have been followed in the literature:

- The first path was suggested by McAfee (1993, footnote 7) and formally investigated by Epstein and Peters (1999). ${ }^{11}$ It consists in redefining the agent's private information as the product of his own preference parameter times the so-called "market information", i.e., what the agent learns from observing other principals' offers. This process leads to an infinite regress since those offers can themselves depend on lower levels of "market information" etc... Epstein and Peters (1999) showed that the whole process converges.

\footnotetext{
${ }^{10}$ The role of a mixed-strategy here is similar to what arises under centralized contracting and limited commitment. Peck (1996) provided some examples. In the context of competing hierarchies, Myerson (1982) already pointed out that truthful equilibria may not exist. He did not suggest analyzing mixed-strategy equilibria. He turned instead to develop the concept of quasi-equilibria which relaxes the truthtelling requirement.

${ }^{11}$ Although in settings where different principals may contract with different sets of agents.
} 
They defined a universal type space and correspondingly a universal space of mechanisms as limits of this infinite regress.

- The second path followed by Peters (2001, 2003), Martimort and Stole (2002) and Page and Monteiro (2003) is to give up the Revelation Principle even in its generalized form sketched above. Indeed, a Revelation Principle is only useful for modelling purposes as far as it allows a characterization of implementable allocations by means of simple incentive constraints. What really matters per se is not the kind of communication that a principal uses with his agent but the set of options that this principal makes available to the agent. Alternatively, the agent could as well choose within this set of alternatives. This is the essence of the so-called "Taxation Principle". ${ }^{12,13}$ Typically, in economic applications with quasi-linear payoffs functions, the space of mechanisms allowing a full description of all pure-strategy equilibrium allocations is the space of nonlinear prices. ${ }^{14}$

Each of these alternative paths has its shortcomings.

First, the Revelation Principle for a universal type space has so far not been used in applications. ${ }^{15}$ The beautiful structure of incentive constraints is lost when one cannot describe the agent's type by a true preference parameter. Moreover, "market information" may sometimes not add much. For instance, in a pure Nash equilibrium, each principal must form beliefs over the others' strategies. Nothing on the offers of other principals is "unknown" when their preferences are common knowledge. ${ }^{16}$ When principals are instead privately informed, the mere offer of their contracts reveals information to the agent. It is then quite natural for each principal to elicit what the agent has learned from others when contracting. ${ }^{17}$

Second, both approaches take generally as granted that an equilibrium exists. The

\footnotetext{
${ }^{12}$ See Rochet (1985) for the Taxation Principle in the case of centralized contracting.

${ }^{13}$ Also called sometimes the "Delegation Principle".

${ }^{14} \mathrm{~A}$ sketch of the argument is as follows. Consider for instance a private common agency game. A pure strategy equilibrium is an array of deterministic mechanisms where any such mechanism stipulates both a price and an action level as a function of the agent's message to each principal. Of course, one can easily prune strategies which are dominated to keep the resulting upper envelope of the price-activity pairs. This yields an array of nonlinear prices which form an equilibrium. See Martimort and Stole (2002).

${ }^{15}$ Calzolari and Pavan (2002) analyzed a dynamic common agency game with secrete contracting and argued that market information can be summarized by the whole vector of past realized contractual choices that the agent may have made with other principals. This confirms that a standard (although somewhat generalized version of the) Revelation Principle applies in this context.

${ }^{16}$ This remark must of course be qualified. Indeed, in a mixed-strategy equilibrium where a principal randomizes over mechanisms, the realizations of this mixture may be observed by the agent before he makes his choices. This adds some dimension of private information that another principal may want to elicit by communicating with the agent.

${ }^{17}$ This is the route followed by Martimort and Moreira (2005). See Section 5 below.
} 
question of existence has only been tackled recently by Page and Monteiro (2003) who showed that, under weak assumptions, there always exists a mixed-strategy equilibrium when principals offer nonlinear prices.

Let us summarize by highlighting one major theme of the existing literature:

Theme 1 : Direct revelation mechanisms generally do not suffice to describe the whole set of equilibrium allocations in a common agency game. ${ }^{18}$ The standard version of the Revelation Principle fails.

Economists seem to have lost there one of their favorite tools. This pessimistic view is not totally correct. Indeed, the Revelation Principle is still useful to compute the payoff of a given principal at a best-response to any array of mechanisms (even indirect ones) offered by others. To illustrate, consider the case of private agency with only two principals. Suppose that the agent has a quasi-linear utility function

$$
U=t_{1}+t_{2}+v\left(q_{1}, q_{2}, \theta\right)
$$

where $q_{i}$ is the activity that the agent undertakes for principal $P_{i}$ and $\theta$ is the adverse selection parameter distributed on some interval $\Theta$.

From Peters (2001, 2003) and Martimort and Stole (2002), there is no loss of generality in looking for equilibria in nonlinear prices $\left\{t_{i}\left(q_{i}\right)\right\}_{i=1,2}$ as far as pure strategies are concerned. However, to compute $P_{i}$ 's best-response to the nonlinear price $t_{-i}(\cdot)$, one can first apply the Revelation Principle and use a direct revelation mechanism $\left\{t_{i}(\hat{\theta}), q_{i}(\hat{\theta})\right\}_{\hat{\theta} \in \Theta}$. This direct mechanism has to implement the same transfer-quantity pairs as the nonlinear price $t_{i}\left(q_{i}\right)$ offered at a best-response to $t_{-i}\left(q_{-i}\right)$. In a second step, one can view the choice of $q_{-i}$ within the options offered by $P_{-i}$ as a non-verifiable variable from $P_{i}$ 's viewpoint since $P_{i}$ cannot contract on it. The methodology of mixed models with adverse selection and moral hazard can then be successfully applied to derive best-responses. ${ }^{19}$ Formally, the agent's indirect utility function vis-à-vis principal $P_{1}$ can be defined as

$$
\hat{U}_{1}\left(q_{1}, \theta\right)=\max _{q_{2} \in Q_{2}} t_{2}\left(q_{2}\right)+v\left(q_{1}, q_{2}, \theta\right)
$$

where $Q_{2}$ is the range of $t_{2}(\cdot)$. This illustrates the role of $q_{2}$ as a moral hazard variable from $P_{1}$ 's viewpoint. In well-structured models, this indirect utility function inherits standard

\footnotetext{
${ }^{18}$ Direct revelation mechanisms might suffice when the agent's utility function is separable in the different activities he undertakes for the principals. For most common agency games of interest, this condition fails. See also Attar and al. (2005) on this issue.

${ }^{19}$ See Laffont and Martimort (2002, Chapter 7) for instance.
} 
properties which make screening models tractable: monotonicity in $\theta$, a (constant-sign) Spence-Mirrlees condition $\frac{\partial^{2} \hat{U}_{1}}{\partial q_{1} \partial \theta}>0$ ( or $\frac{\partial^{2} \hat{U}}{\partial q_{1} \partial \theta}<0$ ), and concavity in $q_{1}$. Standard mechanism design techniques ${ }^{20}$ can then be used to compute best-responses. Sections 3.1 and 4 offer examples. ${ }^{21}$

瑟 The approach consisting in using the standard Revelation Principle to compute bestresponses was pursued by Martimort (1992, 1996a), Ivaldi and Martimort (1994), Martimort and Stole (2003a, 2003b), Mezzetti (1997), Biais, Martimort and Rochet (2000), Calzolari (2001), Laffont and Pouyet (2003), Diaw and Pouyet (2005) and Khalil, Martimort and Parigi (2004). ${ }^{22}$

\section{Equilibria under Complete Information}

Once equipped with the Revelation Principle, standard mechanism design characterizes the set of implementable allocations. Even though the Revelation Principle loses much of its bite in multi-contracting environments, characterizing equilibrium allocations that emerge as equilibria of common agency games remains crucial to understanding how far away those allocations might be from the frontier of incentive feasible allocations achievable under centralized contracting. Such an analysis provides insights on the transaction costs arising under multi-contracting. In this section, I first address this characterization issue in a private agency framework. This highlights two key features of those models: the multiplicity of equilibria; and their systematic inefficiency. I then move on to public agency. Public agency restores efficiency. However, public agency also exacerbates the multiplicity problem. Refinements are needed to pin down an efficient equilibrium outcome.

\footnotetext{
${ }^{20}$ See Laffont and Martimort (2002, Chapter 3).

${ }^{21}$ The last step consists in extending conveniently the nonlinear prices to validate the mere definition of the indirect utility function (6) and its use in computing the other principal's best response. In practice, one might need to enlarge sufficiently the domain $Q_{2}$ where $t_{2}(\cdot)$ is defined to be sure that a first order approach can always be used in computing the maximand of (6). This step was undertaken in Martimort (1992). When studying supply function equilibria, Klemperer and Meyer (1989) used a similar device. Stole (1991) gave conditions on utility functions such that those extensions might not always be needed.

${ }^{22}$ If one redefines the agent's action space so that the agent chooses in fact a nonlinear schedule and not an output, a version of the Revelation Principle might apply in well-structured environments as shown in Peters (2003). This author viewed nonlinear schedules as take-it-or-leave-it offers made by the principals to the agent. A more general mechanism would instead work as follows. First, the principal offers a set of nonlinear prices; second, the agent chooses one of these prices, and finally, the principal himself chooses a particular output. Some might argue that this approach gives too much freedom to the modeler in redefining the agent's action space.
} 


\subsection{Private Agency and Direct Externalities}

Consider Example $3 .^{23}$ For simplicity, I now analyze a model with private and intrinsic agency ${ }^{24}$ and assume that the manufacturer's cost parameter $\theta$ is common knowledge. Principals might now a priori offer the nonlinear prices $\left\{t_{i}\left(q_{i}\right)\right\}_{i=1,2}$ based only on the quantities they respectively buy from the agent. ${ }^{25}$ As a benchmark, consider first the case where they use direct revelation mechanisms which, under complete information, leave a single option to the agent. These mechanisms can thus be identified with simple forcing contracts $\left\{\left(t_{i}, q_{i}\right)\right\}_{i=1,2}$.

Under intrinsic agency, the agent accepts both contracts when:

$$
t_{1}+t_{2}-\theta C\left(q_{1}+q_{2}\right) \geq 0 .
$$

At a best-response, each principal reduces his own payment to the agent up to the point where the participation constraint (7) binds. Inserting the corresponding value of the transfer $t_{i}$ into $P_{i}$ 's objective function, it is easy to see that this principal wants to implement an output $q_{i}$ which maximizes the payoff of his bilateral coalition with the agent:

$$
q_{i} \in \arg \max _{\tilde{q}_{i}} P\left(\tilde{q}_{i}+q_{-i}\right) \tilde{q}_{i}+t_{-i}-\theta C\left(\tilde{q}_{i}+q_{-i}\right) .
$$

This bilateral efficiency requirement is key to any common agency game. We will encounter it under various forms in the sequel. The important issue is to understand how inefficiencies may arise when all contracts are bilaterally efficient.

The corresponding first order condition for bilateral efficiency characterizes the (unique) Nash equilibrium of this game. This is the "Cournot" outcome, $q_{1}(\theta)=q_{2}(\theta)=q^{c}(\theta)$ where $q^{c}(\theta)$ solves:

$$
P^{\prime}\left(2 q^{c}(\theta)\right) q^{c}(\theta)+P\left(2 q^{c}(\theta)\right)=\theta C^{\prime}\left(2 q^{c}(\theta)\right) .
$$

Let us turn to the case where principals might now offer any nonlinear price defined over some larger domain $Q_{i}$. This expansion of the strategy space adds some flexibility to assess how a principal may react to unexpected changes in the agent's output. This flexibility generates new equilibrium outcomes. Nevertheless, bilateral efficiency still implies

\footnotetext{
${ }^{23}$ This vertical contracting model is drawn from Martimort and Stole (2003a).

${ }^{24}$ Intrinsic common agency may be justified when the agent wants to preserve some form of ex post competition between retailers or if the agent has made some specific investment which can be recovered only if both retailers use his product.

${ }^{25}$ Again, from Peters $(2001,2003)$ and Martimort and Stole (2002), this is the appropriate space of mechanisms to consider in this private agency context.
} 
that $P_{i}$ maximizes the payoff of the bilateral coalition he forms with the agent:

$$
q_{i} \in \arg \max _{\tilde{q}_{i}} P\left(\tilde{q}_{i}+q_{-i}^{*}\left(\tilde{q}_{i}\right)\right) \tilde{q}_{i}+t_{-i}\left(q_{-i}^{*}\left(\tilde{q}_{i}\right)\right)-\theta C\left(\tilde{q}_{i}+q_{-i}^{*}\left(\tilde{q}_{i}\right)\right)
$$

where $q_{-i}^{*}(\cdot)$ satisfies the first order condition: ${ }^{26}$

$$
\frac{\partial t_{-i}^{*}}{\partial q_{-i}}\left(q_{-i}^{*}\left(\tilde{q}_{i}\right)\right)=\theta C^{\prime}\left(\tilde{q}_{i}+q_{-i}^{*}\left(\tilde{q}_{i}\right)\right) \text { for all } \tilde{q}_{i} \in Q_{i}
$$

Using the first order condition for (9) and equation (10), one can easily check that a symmetric equilibrium output $q^{e}$ solves:

$$
P^{\prime}\left(2 q^{e}\right) q^{e}\left(1+\frac{\partial q_{-i}^{*}\left(q^{e}\right)}{\partial q_{i}}\right)+P\left(2 q^{e}\right)=\theta C^{\prime}\left(2 q^{e}\right)
$$

Any output between Cournot (corresponding to $\frac{\partial q_{-i}^{*}}{\partial q_{i}}\left(q^{e}\right)=0$ or to simple forcing contracts) and Bertrand (corresponding to $\frac{\partial q_{-i}^{*}}{\partial q_{i}}\left(q^{e}\right)=-1$ ) can be sustained at equilibrium by specifying appropriate nonlinear prices for out of equilibrium outputs. ${ }^{27}$ The intuition for these rather competitive outcomes is as follows. By offering a fairly flat schedule around the equilibrium point, a principal, say $P_{-i}$, makes the agent eager to produce more for him if $P_{i}$ reduces the amount he buys from the agent. $P_{i}$ has no incentives to deviate since he fears that $P_{-i}$ will flood the market following such deviation.

This example illustrates that out of equilibrium messages have a powerful strategic value in models with direct externalities between the principals. In our vertical contracting example, this strategic concern makes equilibrium outcomes more competitive than the Cournot outcome achieved with direct mechanisms. ${ }^{28,29}$

\footnotetext{
${ }^{26}$ This is sufficient provided that $t_{-i}^{*}(\cdot)$ is concave enough.

${ }^{27}$ Quadratic extensions of $t_{i}\left(q_{i}\right)$ for out-of equilibrium transfer-output pairs suffice. Of course, the choice of those quadratic extensions should ensure the concavity of the agent's objective function. These second order conditions put constraints on the lower and upper bounds of the set of equilibrium outputs.

${ }^{28}$ Consider now that the two retailers are on two unrelated markets and enjoy monopoly power on each. $P_{1}$ 's profit does not depend on $q_{2}$ and vice versa. There is no longer any direct externality between principals. It is easy to check (see Martimort and Stole (2003a)) that the efficient outcome is sustained in equilibrium. It is achieved both with direct revelation mechanisms (forcing contracts) but also with more general nonlinear prices. This points at the crucial role that direct externalities play to create a strategic role to the extensions of the nonlinear prices off the equilibrium. This also illustrates one limit of Theme 1 since, in this case, the standard version of the Revelation Principle holds.

${ }^{29}$ Consider now the price competition version of the game. Contracts now depend on the final retail prices of the goods, i.e., they are of the form $t_{i}\left(p_{i}\right)(i=1,2)$. Goods are differentiated with respective demands $D_{i}\left(p_{i}, p_{-i}\right)$. Profit functions for the retailers and the manufacturers are given by

$$
V_{i}=p_{i} D_{i}\left(p_{i}, p_{-i}\right)-t_{i}, \quad i=1,2 \text { and } U=t_{1}+t_{2}-\theta C\left(D_{1}\left(p_{1}, p_{2}\right)+D_{2}\left(p_{1}, p_{2}\right)\right) .
$$

Nonlinear prices help enforce equilibrium outcomes that are more collusive than the differentiated Bertrand outcome achieved with forcing contracts stipulating only a lump-sum payment and a retail price $\left\{\left(t_{i}, p_{i}\right)\right\}(i=1,2)$. The intuition is exactly the reverse of that in the quantity game.
} 
Theme 2 : Out of equilibrium messages have a strategic value in models with direct externalities and private agency. Equilibrium outcomes may be inefficient even under complete information.

Segal and Whinston (2003) and Martimort and Stole (2003a) characterized Nash outcomes under either intrinsic or delegated common agency and showed their multiplicity. ${ }^{30}$ Segal and Whinston (2003) also compared common agency with the game where the agent makes offers. ${ }^{31}$ Parlour and Rajan (2001) presented an interesting model of competition between lenders under complete information. That the common agent may default introduces an incentive constraint to induce repayment. ${ }^{32}$ Principals interact through this constraint: the contract offered by a lender bestows a negative externality on others since the agent reneges on all contracts if he reneges at all. Multi-contracting can lead to non-competitive pricing if the agent's incentives to default are strong enough.

\subsection{Public Agency}

Public agency makes coordination between principals easier because they now contract on more variables than under private agency. The good side of expanding the contract space is thus that efficiency is restored. Its bad side is that the multiplicity problem is also exacerbated.

- Coordination: Staying with our vertical contracting example, consider the case of public agency. Both principals can now contract on the whole vector of outputs $\left(q_{1}, q_{2}\right)$. Actually, contracts depending on the total output $q=q_{1}+q_{2}$ sold on the final market suffice to highlight the coordination problem in this context. Relabelling transfers so that

\footnotetext{
${ }^{30}$ See also D'Aspremont and Dos Santos Ferreira (2005).

${ }^{31}$ The multiplicity of common agency equilibria is reminiscent of the multiplicity found in the vertical contracting literature where the agent makes secret offers to principals. The multiplicity arises there from the leeway in specifying beliefs on what contracts other principals receive when a given principal observes that the agent deviates. See O'Brien and Shaffer (1992), McAfee and Schwartz (1994) and Segal (1999) among others. With passive beliefs, each principal conjectures that others still receive the equilibrium contract following an unexpected deviation. Exactly as with direct mechanisms or forcing contracts in the common agency game, the Cournot outcome emerges. The vertical contracting literature has also investigated the case of symmetric beliefs such that, once the agent deviates vis-à-vis a principal, the latter thinks that others receive those alternative offers as well. Of course, in symmetric environments, such symmetric beliefs sustain the monopoly outcome which cannot be replicated under common agency. Indeed, under common agency, subgame-perfection requires that the agent substitutes a little bit more of production of good $i$ against a little bit less of production of good $-i$ so that a simultaneous output reduction never arises.

${ }^{32}$ To make it precise, this incentive constraint is not due to asymmetric information but stems from the impossibility to enforce repayments.
} 
principals offer the agent contracts $s_{i}(q)$ specifying the shares of the grand-coalition's payoff they request respectively, payoffs can be written as:

$$
V_{i}=s_{i}(q), \quad \text { for } \quad i=1,2 \quad \text { and } \quad U=q P(q)-\theta C(q)-s_{1}(q)-s_{2}(q) \text {. }
$$

Any output $\bar{q}$ giving a positive profit to the grand-coalition of the principals and the agent (i.e., such that $P(\bar{q}) \bar{q}-\theta C(\bar{q}) \geq 0$ ) arises at equilibrium with simple forcing contracts. Suppose indeed that $P_{-i}$ insists on a forcing contract of the kind $s_{-i}(q)=$ $\left\{\begin{array}{ll}\bar{s}_{-i} & \text { if } q=\bar{q} \\ +\infty & \text { if } q \neq \bar{q},\end{array}\right.$ for some pair $\left(\bar{q}, \bar{s}_{-i}\right)$ and that no production takes place when principals insist on different outputs. Principal $P_{i}$ 's best-response to such an offer by $P_{-i}$ cannot influence total production since the agent either produces $\bar{q}$ or refuses contracting. Any non-negative payoff pair $\left(\bar{s}_{1}, \bar{s}_{2}\right)$ such that $P(\bar{q}) \bar{q}-\theta C(\bar{q})-\bar{s}_{1}-\bar{s}_{2}=0$ is an equilibrium.

In sharp contrast with private agency, public agency only entails transaction costs when principals fail to coordinate. This point was already stressed by Bernheim and Whinston (1986b)'s early investigation of delegated common agency games. ${ }^{33}$

Theme 3 : Under public agency and complete information, common agency games may be plagued with inefficient equilibria: a coordination problem.

Altogether, Themes 2 and 3 show that extending the contracting spaces available to both principals by moving from private to public agency enlarges also the set of implementable outcomes. The comparison of the equilibrium sets with private and public agency also highlights how transaction costs change when the degree of contractual incompleteness increases as one moves from public to private agency.

• "Truthfulness" as an Equilibrium Refinement: As shown above, there nevertheless exists an equilibrium of the public agency game under complete information which implements an efficient outcome. Our concerns should now be quite similar to those of the implementation literature. Can we find a class of strategies which ensures that efficiency is always reached at equilibrium? If yes, multi-contracting does not preclude efficiency at least under complete information. This question has been addressed by Bernheim and Whinston (1986b), albeit in the context of delegated common agency. Their insight can be best understood once one has in mind a standard result from Incentive Theory. Under

\footnotetext{
${ }^{33}$ See also the earlier contribution of Wilson (1979).
} 
complete information, ${ }^{34}$ a principal can always delegate to his agent the choice of an optimal action from the point of view of their bilateral coalition by making this agent residual claimant. This is achieved with a "sell-out" contract of the form $t_{i}(q)=S_{i}(q)-k_{i}$, where $S_{i}(q)$ is $P_{i}^{\prime}$ 's benefit when action $q$ is chosen and $k_{i}$ is $P_{i}^{\prime}$ 's payoff from this delegation.

To understand more precisely the role of "sell-out" contracts, let us come back to Example 2 on lobbying under complete information. To compute $P_{i}$ 's best-response to an aggregate scheme offered by other principals $t_{-i}(\cdot)$, I proceed as under private agency. An output $q$ is implemented at equilibrium by a nonlinear price $t_{i}(\cdot)$ when the transfer $t_{i}(q)=t_{i}$ is reduced up to the point where the agent's participation constraint is binding. Under delegated common agency, this participation constraint accounts for the fact that the agent may choose among the different contracts offered. It can be written as:

$$
t_{i}+t_{-i}(q)-\theta C(q)=\max \left\{0, \max _{\{I \subset N-\{i\}, q\}} T_{I}(q)-\theta C(q)\right\},
$$

where $T_{I}(q)=\sum_{i \in I} t_{i}(q)$ denotes the aggregate transfer offered by a set $I$ of principals. ${ }^{35}$ Given that transfer $t_{i}, P_{i}$ wants to induce a production $q$ which maximizes $S_{i}(q)-t_{i}$. This amounts again to choosing an output $q$ which maximizes the bilateral payoff of the coalition he forms with the agent: 36

$$
q \in \arg \max _{\tilde{q}} S_{i}(\tilde{q})+t_{-i}(\tilde{q})-\theta C(\tilde{q}) .
$$

Suppose that all other principals $P_{j}$ for $j \neq i$ offer so-called truthful schedules, of the form $t_{j}(q)=\max \left\{0, S_{j}(q)-k_{j}\right\}$ for some constants $k_{j}$. These schedules correspond to the non-negative part of sell-out contracts. Assuming differentiability at the equilibrium point $q$, bilateral efficiency implies:

$$
S_{i}^{\prime}(q)+t_{-i}^{\prime}(q)=\theta C^{\prime}(q)
$$

The agent's optimal output solves instead:

$$
q \in \arg \max _{\tilde{q}} T_{N}(\tilde{q})-\theta C(\tilde{q})
$$

\footnotetext{
${ }^{34}$ If the agent is risk-neutral, this is true more generally under ex ante contracting even when there is adverse selection or moral hazard. See Laffont and Martimort (2002, Chapters 2 and 4).

${ }^{35}$ The right-hand side of (12) takes into account that the agent has several options, either refusing all offers or taking only contracts from a coalition $I$ which would not include $P_{i}$. If (12) was not an equality, $P_{i}$ could reduce his own contribution and still induce acceptance, a contradiction.

${ }^{36}$ From (12), it appears also that $t_{i}(q) \geq 0$ for the quantity $q$ that $P_{i}$ wants to induce. Given that all principals offer positive contributions, the agent accepts all contracts. Denoting then by $q_{-i}$ the equilibrium output chosen by the agent to maximize the right-hand side of (12), we have $q_{-i}=\arg \max _{\{N-\{i\}, q\}} T_{N-\{i\}}(q)-\theta C(q)$. Then, from (13), we can show that $S_{i}(q)-t_{i}(q) \geq S_{i}\left(q_{-i}\right)$. This condition can be interpreted as an individual rationality constraint for $P_{i}$. An immediate consequence is that, necessarily $S_{i}(q) \geq S_{i}\left(q_{-i}\right)$. By making a positive contribution, $P_{i}$ shifts the agent's decision towards his own preferences.
} 
Assuming concavity of this objective and that the maximum is achieved at an interior point where contributions are positive yields the following first order condition:

$$
T_{N}^{\prime}(q)=t_{i}^{\prime}(q)+t_{-i}^{\prime}(q)=\theta C^{\prime}(q)
$$

Using the fact that principals $P_{j}$ for $j \neq i$ offer truthful schedules yields:

$$
t_{i}^{\prime}(q)=S_{i}^{\prime}(q)
$$

At an equilibrium output $q$, the marginal contribution of a principal reflects his own marginal valuation. This condition can also be extended for any quantity which is not offered at equilibrium as long as the corresponding contribution remains positive. This gives the expression of the truthful schedule offered by $P_{i}$ :

$$
t_{i}(q)=\max \left\{0, S_{i}(q)-k_{i}\right\} \quad \text { for some } \quad k_{i}
$$

Because each principal makes a contribution which reflects his own marginal valuation, ${ }^{37}$ the equilibrium quantity is necessarily efficient for the grand-coalition made of all principals and the agent. As a refinement of the equilibrium set, truthfulness ensures efficiency. ${ }^{38}$

- Consequences of "Truthfulness" for Equilibrium Payoffs: Under delegated common agency, "truthfulness" has strong implications for the principals' equilibrium payoffs. Indeed, the agent's binding participation constraint (12) yields a set of inequality constraints that must be satisfied by any vector $\left(k_{i}\right)_{1 \leq i \leq n}$ of payoffs for the principals:

$$
W_{N}-k_{N}=\max _{I \in N}\left\{0, W_{I}-k_{I}\right\}
$$

where $W_{I}=\max _{q}\left\{S_{I}(q)-\theta C(q)\right\}$ is the aggregate surplus of a coalition $I$ of principals. The fact that the schedule is everywhere truthful plays a key role to compute the righthand side of (17) since, even when the agent chooses to contract only with a subset of principals, he continues to choose an efficient output from the point of view of the coalition he forms with these principals. Truthfulness affects the agent's reservation payoff, and thus feed-backs on the principals' payoffs.

Theme 4 : Truthful schedules solve the coordination problem but have strong implications on the principals' equilibrium payoffs in a delegated common agency game.

\footnotetext{
${ }^{37}$ At least on its positive part.

${ }^{38}$ Our notion of efficiency concerns only the grand-coalition. This notion of efficiency should of course be distinguished from social welfare maximization. In a lobbying context, the definition of social welfare would also incorporate non-active interest groups.
} 
逼相

The structure of payoffs in a delegated common agency game has been investigated by Laussel and Lebreton (2001) and Milgrom (2004). ${ }^{39}$ This structure is deeply linked to the property of the characteristic function $W_{I}$. When $S_{i}^{\prime}>0$ for all $i$, principals have congruent preferences. The agent gets no rent under delegated common agency and the existence of a vector $\left(k_{i}\right)_{1 \leq i \leq n}$ so that $W_{N}-k_{N}=0 \geq W_{I}-k_{I} \forall I \subset N$ follows from the sub-additivity of $W_{I}$. When principals have more conflicting preferences, the agent may instead get a positive rent.

Prat and Rustichini (2003) analyzed a multiprincipals-multiagents game when there is no externality across agents. Efficiency is strongly linked to the existence of a pure strategy equilibrium in the normal form game. They also generalized the link between the principals' payoffs under common agency and the characteristic function of some cooperative game. On this issue see also Perez-Castrillo (1994). Bergemann and Valimaki (2003) analyzed dynamic common agency games under complete information. They described payoffs for Markov-perfect truthful equilibria.

The public agency model above has been an important part of political economists' toolkit over the past ten years following Grossman and Helpman (1994, 2002). See also Helpman (1997), Rama and Tabellini (1998), Mitra (1999) and Helpman and Persson (2001) among many others. Dixit, Grossman and Helpman (1997) introduced redistributive concerns.

- More on Refinements: An important issue is to find a rationale for truthful menus since it might seem hard to justify that principals would offer a complete list of options without any concerns for copying with uncertainty or adverse selection. Following Bernheim and Whinston (1986b), one might select those equilibria because they are coalition-proof, i.e., immune to deviations by subsets of principals which are themselves immune to deviations by sub-coalitions, etc... Coalition-proof equilibrium payoffs can be implemented with truthful schedules in environments with quasi-linear utility functions. ${ }^{40}$ Truthful menus can also cope with uncertainty on the agent's cost function. Laussel and Lebreton (1998) studied a public good context when contracts are offered by contributors

\footnotetext{
${ }^{39}$ See also De Villemeur and Versaevel (2003).

${ }^{40}$ Although attractive, this approach has three weaknesses. First, it does not per se disqualify nontruthful strategies that would sustain the same payoffs. Second, in more complex environments, one can find common agency equilibria with truthful schedules which are not coalition-proof (see Konishi, Lebreton and Weber (1999)). Lastly, Kirchsteiger and Prat (2001) presented experimental evidences showing that principals may prefer using simpler "forcing contracts".
} 
ex ante, i.e., before the agent learns about his cost function. ${ }^{41}$ Under ex ante contracting, incentive compatibility ensures that, for any realization of the underlying uncertainty, marginal contributions reflect the principals' preferences. ${ }^{42}$

\section{Equilibria under Adverse Selection}

\subsection{Private Agency with Indirect Externalities}

Section 3.1 has shown how inefficiencies arise in models with private agency and direct externalities, even under complete information. To stress another source of inefficiency under multi-contracting, consider a case without direct externality but with private information on the agent's side. To fix ideas, let us modify slightly Example 1. Two regulators are interested in controlling two different activities of a regulated firm, say outputs $q_{1}$ and $q_{2}$. The regulators' and the firm's objective functions are

$$
V_{i}=S_{i}\left(q_{i}\right)-t_{i}, \quad i=1,2 \quad \text { and } U=t_{1}+t_{2}-\theta C\left(q_{1}, q_{2}\right)
$$

where $S_{i}(\cdot)$ is now the strictly concave return of activity $i$ and $C(\cdot)$ is strictly convex in $q=\left(q_{1}, q_{2}\right)$. There are no direct externalities between principals. The two activities are complements when $C_{12}<0$, and substitutes when $C_{12}>0$. The technological parameter $\theta$ is the firm's private information only.

I use now the methodology already reviewed in Section 2. Let us define the indirect cost function of the agent vis-à-vis $P_{1}$ as

$$
\tilde{C}\left(q_{1}, \theta\right)=\min _{q_{2} \in Q_{2}} \theta C\left(q_{1}, q_{2}\right)-t_{2}\left(q_{2}\right)
$$

for a given nonlinear schedule $t_{2}(\cdot)$ (defined over some range $Q_{2}$ ) offered by $P_{2}$.

Let $q_{2}^{*}\left(q_{1}, \theta\right)$ denote the best choice of $q_{2}$ by the agent when his type is $\theta$ and he chooses an activity $q_{1}$ for $P_{1}$. Provided that the first order condition below is also sufficient, $q_{2}^{*}\left(q_{1}, \theta\right)$ is defined implicitly by:

$$
t_{2}^{\prime}\left(q_{2}^{*}\left(q_{1}, \theta\right)\right)=\theta C_{2}\left(q_{1}, q_{2}^{*}\left(q_{1}, \theta\right)\right) .
$$

\footnotetext{
${ }^{41}$ The role of uncertainty in restricting equilibrium sets is already well-known from the related literature on supply functions. See Klemperer and Meyer (1989).

${ }^{42}$ Equilibrium marginal contributions do not depend on the underlying distribution of types, something that can be puzzling. Another well-known problem with ex ante contracting is that transfers might no longer be positive for all realizations of the cost parameter. Ex post, the agent would prefer to renege on a contract if it turns out to stipulate a negative contribution. Martimort and Semenov (2005) studied that enforcement issue and how it leads to inefficient contracting outcomes in a lobbying context.
} 
Simple differentiation shows that raising the level of activity $q_{1}$ shifts also $q_{2}$ downwards (resp. upwards) when activities are substitutes (resp. complements) since $\frac{\partial q_{2}^{*}}{\partial q_{1}}<0$ (resp. $\left.\frac{\partial q_{2}^{*}}{\partial q_{1}}>0\right)$.

Consider the optimal output choice that $P_{1}$ wants to induce from an agent with such an indirect cost function $\tilde{C}\left(q_{1}, \theta\right)$. To compute $P_{1}$ 's best-response, we may restrict the analysis to direct revelation mechanisms $\left\{t_{1}(\hat{\theta}), q_{1}(\hat{\theta})\right\}_{\hat{\theta} \in \Theta}$ and, as suggested in Section 2, apply the Revelation Principle for a given nonlinear schedule $t_{2}(\cdot)$ offered by $P_{2}$. Pointwise optimization of $P_{1}$ 's objective yields: ${ }^{43}$

$$
S_{1}^{\prime}\left(q_{1}(\theta)\right)=\tilde{C}_{1}\left(q_{1}(\theta), \theta\right)+\frac{F(\theta)}{f(\theta)} \tilde{C}_{1 \theta}\left(q_{1}(\theta), \theta\right) .
$$

This is a condition for bilateral incentive efficiency. The contract between $P_{1}$ and the agent maximizes their coalitional payoff. However, costs are now replaced by virtual costs under adverse selection. Using the Envelope Theorem, (18) becomes:

$$
S_{1}^{\prime}\left(q_{1}(\theta)\right)=\left(\theta+\frac{F(\theta)}{f(\theta)}\right) C_{1}\left(q_{1}(\theta), q_{2}^{*}\left(q_{1}(\theta), \theta\right)\right)+\frac{F(\theta)}{f(\theta)} C_{2}\left(q_{1}(\theta), q_{2}^{*}\left(q_{1}(\theta), \theta\right)\right) \frac{\partial q_{2}^{*}}{\partial q_{1}} .
$$

Had the principals merged and offered cooperatively their contracts to the agent, the optimal output $q_{1}$ would instead satisfy: ${ }^{44}$

$$
S_{1}^{\prime}\left(q_{1}(\theta)\right)=\left(\theta+\frac{F(\theta)}{f(\theta)}\right) C_{1}\left(q_{1}(\theta), q_{2}(\theta)\right) .
$$

Under centralized contracting, the outcome is interim efficient. Comparing (19) and (20) highlights the new frictions involved under common agency. The common agency outcome departs from the cooperative solution by the new term $\frac{F(\theta)}{f(\theta)} C_{2}\left(q_{1}, q_{2}^{*}\left(q_{1}, \theta\right)\right) \frac{\partial q_{2}^{*}}{\partial q_{1}}$ on the right-hand side of (19).

When outputs are substitutes $\left(\frac{\partial q_{2}^{*}}{\partial q_{1}}<0\right)$ distortions are smaller under common agency than under centralized contracting. Intuitively, each principal would prefer the other to think that the agent is of a lower type than what he really is. By inducing the agent to exert less activity for $P_{2}, P_{1}$ finds it less costly to decrease output $q_{1}$ for rent extraction purposes. The contractual externality between principals is positive. In equilibrium, output distortions are reduced compared with the cooperative solution.

When outputs are complements $\left(\frac{\partial q_{2}^{*}}{\partial q_{1}}>0\right)$, the opposite holds. Each principal still prefers the other to think that the agent is of a lower type. However, this is now ob-

\footnotetext{
${ }^{43}$ Provided again that the solution $q_{1}(\theta)$ of $(18)$ is monotonically decreasing to satisfy the second order condition.

${ }^{44} \mathrm{~A}$ similar condition holds for $q_{2}(\theta)$.
} 
tained by exacerbating output distortions compared with the cooperative outcome. The contractual externality is negative.

Theme 5 : With adverse selection and indirect externalities only, outputs are distorted in the intrinsic common agency game compared with the cooperative outcome. The direction of the distortion depends on whether the activities controlled by the principals are substitutes or complements in the agent's utility function.

To sharpen intuition, consider the case where $S_{1}(\cdot)=S_{2}(\cdot)=S(\cdot)$ and $C(\cdot)$ is symmetric in $\left(q_{1}, q_{2}\right)$. Using (19), a symmetric equilibrium $q(\theta)$ satisfies the differential equation: ${ }^{45}$

$$
S^{\prime}(q(\theta))=\left(\theta+\frac{F(\theta)}{f(\theta)}\right) C_{1}(q(\theta), q(\theta))+\frac{F(\theta)}{f(\theta)} \frac{\theta C_{12}(q(\theta), q(\theta)) C_{2}(q(\theta), q(\theta)) \dot{q}(\theta)}{C_{2}(q(\theta), q(\theta))+\theta C_{12}(q(\theta), q(\theta)) \dot{q}(\theta)}
$$

Two polar cases are worth studying:

- Perfect complementarity: We can write $C\left(q_{1}, q_{2}\right)=\hat{C}\left(\min \left(q_{1}, q_{2}\right)\right)$ for some increasing and convex function $\hat{C}(\cdot)$. Since $C_{12}(q, q)=\infty$, in the limit $(21)$ becomes

$$
2 S^{\prime}(q(\theta))=\left(\theta+2 \frac{F(\theta)}{f(\theta)}\right) \hat{C}^{\prime}(q(\theta)) .
$$

This is similar to the public agency case treated in Section 4.3 below.

- Perfect substitutes: Suppose now that $C\left(q_{1}, q_{2}\right)=\hat{C}\left(q_{1}+q_{2}\right)$. Condition (21) becomes:

$$
S^{\prime}(q(\theta))=\left(\theta+\frac{F(\theta)}{f(\theta)}\left(1+\frac{\theta \hat{C}^{\prime \prime}(2 q(\theta)) \dot{q}(\theta)}{\hat{C}^{\prime}(2 q(\theta))+\theta \hat{C}^{\prime \prime}(2 q(\theta)) \dot{q}(\theta)}\right)\right) \hat{C}^{\prime}(2 q(\theta)) .
$$

Given that competition between principals reduces distortions, an important issue is whether the first-best outcome $q^{*}(\theta)$ can be achieved at an equilibrium. (23) shows that this might not always be the case. ${ }^{46}$

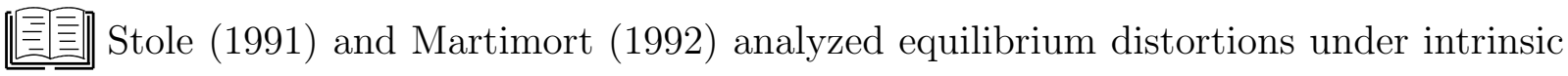
and private common agency and asymmetric information. When symmetric principals control complementary activities, a multiplicity of equilibria exists and levels of activities

\footnotetext{
${ }^{45}$ The initial condition is $q(\underline{\theta})=q^{*}(\underline{\theta})$ where the first-best outcome $q^{*}(\theta)$ satisfies $S^{\prime}\left(q^{*}(\theta)\right)=$ $\theta C_{1}\left(q^{*}(\theta), q^{*}(\theta)\right)$. See Stole (1991) and Martimort (1992) for details.

${ }^{46}$ One has actually $\left(S^{\prime \prime}\left(q^{*}(\theta)\right)-2 \theta \hat{C}^{\prime \prime}\left(2 q^{*}(\theta)\right)\right) \dot{q}^{*}(\theta)=\hat{C}^{\prime}\left(2 q^{*}(\theta)\right)$, and (23) holds only when $S^{\prime \prime}=0$. Even though both principals compete fiercely to attract the agent's services, the symmetric output is generally still below the first-best. Stole (1991) and Martimort (1992) gave examples, with perfect substitutes and quadratic cost functions, such that the equilibrium output is first-best.
} 
in those equilibria can be ranked. Uniqueness arises with substitutes. ${ }^{47}$ With quadratic utility functions and beta-distributions, existence and characterization of an equilibrium with quadratic nonlinear contracts are obtained. Gal-Or (1991) and Martimort (1996a) used such characterizations to compare manufacturers-retailers structures under adverse selection. Manufacturers tend to choose a common retailer when they sell complement goods whereas exclusive dealing dominates otherwise. Mezzetti (1997) analyzed a model where two manufacturers sell differentiated products to a customer with an unknown preference parameter. Some types prefer to consume one good whereas others prefer the other. Although goods are substitutes, output distortions are exacerbated at equilibrium. This is due to the fact that principals have opposite rankings of the agent's type.

The private agency framework under adverse selection has also been used to study competing regulations in open economies (see Bond and Gresik (1996), Olsen and Osmudsen (2001, 2003), Calzolari (2001) and Laffont and Pouyet (2003)). A multinational firm may play national regulators one against the others to secure more information rent.

Biais, Martimort and Rochet (2000) analyzed competition among market-makers on financial markets. Investors have private information on their liquidity needs and on the value of an asset. Market-makers stand ready to provide liquidity according to nonlinear price-quantity schedules. There is a common value aspect in the model: the value of the asset for the market-makers is linked to the investors' signals. Because of this, ex post efficiency is not reached in the limit of a large number of market-makers although the limit equilibrium remains interim-efficient.

Biglaiser and Mezzetti (1993) analyzed a model where two principals compete for the exclusive services of an agent under both moral hazard and adverse selection. Principals are differentiated: one is relatively efficient at large output levels, the other is more efficient at low levels. In equilibrium, the most (resp. less) efficient agents deal with the high (resp. low) output principal. Principals compete fiercely for intermediate types.

Firms competing through nonlinear prices on oligopoly markets might want to choose which customers to target. To fully understand the welfare consequences of competitive screening, one must ask whether competition increases market coverage. Martimort and Stole (2003b) tackled this issue. Competition with delegated agency and substitutes leads to lower participation distortions relative to monopoly whereas intrinsic agency or dele-

\footnotetext{
${ }^{47}$ This multiplicity comes from the fact that the differential equation (21) is not Lipschitz at $\underline{\theta}$ and has a singularity. The behavior of the solutions and, in particular, its uniqueness depends on the local behavior at $\underline{\theta}$, which itself depends on whether the activities of the agent are complements or substitutes.
} 
gated agency with demand complements lead to greater distortions. On delegated versus intrinsic common agency games, see also Calzolari and Scarpa (1999). The literature on competition under nonlinear pricing is covered by Stole (2005).

\subsection{Private Agency with Direct Externalities}

The strategic role of nonlinear schemes was already stressed in Section 3.1. To justify the use of such schemes, one may want to introduce an adverse selection parameter in the agent's preferences so that principals use such schemes also for screening purposes. One may then ask how adverse selection affects the strategic value of contracts. Under adverse selection, the slope of a nonlinear price is now determined by incentive compatibility. This requirement is strong enough to significantly reduce the equilibrium set compared with complete information where the sole role of nonlinear prices is strategic. Moreover, the screening role of the contracts may call for lower levels of activities which might countervail their strategic role. Take for instance the case of two principals suffering from direct externalities as in Section 3.1. Whereas private agency under complete information induces high levels of outputs, adverse selection on the agent's cost may require to decrease those outputs, reducing thereby the strategic value of contracts.

Theme 6 : Under adverse selection and direct externalities, the strategic role of nonlinear prices might be reduced.

瞎 Khalil, Martimort and Parigi (2004) analyzed interactions between financiers providing funds to an agent who has private information on his income. Two institutions are compared. Under public agency, lenders undertake monitoring activities which are publicly verifiable and there is no direct externality between those principals. Under private agency, monitoring by either lender is private but still contractible with the agent. In both cases, each principal benefits from the other doing some monitoring since this may publicly reveal the agent's income. This introduces a direct externality between principals under private agency. The nature of the contractual externalities depends on the institution chosen. Under public agency, a lender wants to trick the other into believing that the agent has a lower income and does so by increasing monitoring. This reduces the loan repayment requested by the other and increases the share of income that can be kept by the first lender. There is excessive monitoring in equilibrium and equity-like contracts emerge. Under private agency, a given lender reduces his own contribution to 
the overall monitoring effort. Monitoring diminishes and may disappear at high income levels. Debt-like payments with flat repayments arise.

\subsection{Public Agency}

Under asymmetric information, the equilibrium nonlinear schedules no longer reflect the principals' marginal valuations contrary to what happens with "truthful" equilibria under complete information. This has important consequences both for efficiency but also for the distribution of principals' payoffs under delegated common agency.

I shall first use Example 1 on regulation and focus on the intrinsic common agency game. The $n$ regulators offer non-cooperatively the nonlinear prices $\left\{t_{i}(q)\right\}_{1 \leq i \leq n}$ to the common agent whose type $\theta$ is private information. In the case of a linear cost function (i.e., $C(q)=q$ ), the agent's rent when taking all contracts is:

$$
U(\theta)=\max _{q} \sum_{i=1}^{n} t_{i}(q)-\theta q
$$

Assuming concavity of the agent's objective, we have at any differentiability point $q(\theta)$ :

$$
\sum_{i=1}^{n} t_{i}^{\prime}(q(\theta)=\theta .
$$

Proceeding as usual to compute $P_{i}$ 's best-response, we obtain:

$$
q(\theta) \in \arg \max _{\tilde{q}} S_{i}(\tilde{q})+t_{-i}(\tilde{q})-\left(\theta+\frac{F(\theta)}{f(\theta)}\right) \tilde{q} \quad \forall i \in\{1, \ldots, n\} .
$$

Again, the equilibrium quantity satisfies a bilateral interim efficiency condition. Assuming concavity of $P_{i}$ 's objective, the first order condition for (25) yields: ${ }^{48}$

$$
S_{i}^{\prime}(q(\theta))+t_{-i}^{\prime}(q(\theta))=\theta+\frac{F(\theta)}{f(\theta)}, \quad \forall i \in\{1, \ldots, n\} .
$$

From (24) and (26), $P_{i}$ 's marginal contribution at any equilibrium point satisfies

$$
t_{i}^{\prime}(q)=S_{i}^{\prime}(q)-\frac{F(\theta(q))}{f(\theta(q))}
$$

where $\theta(q)$ is the inverse function of $q(\theta)$ defined in (28) below. ${ }^{49}$

Under adverse selection, each principal reduces the common agent's production to better extract his rent. Each principal bears the full cost of information revelation but only

\footnotetext{
${ }^{48}$ This is the equilibrium condition provided a standard monotonicity condition holds.

${ }^{49}$ To ensure that $q(\cdot)$ is monotonically decreasing, we need to assume that $\frac{d}{d \theta}\left(\frac{F(\theta)}{f(\theta)}\right)>0$.
} 
enjoys a part of its benefit. Marginal contributions are below their complete information values and the equilibrium output is reduced with respect to the cooperative outcome:

$$
\sum_{i=1}^{n} S_{i}^{\prime}(q(\theta))=\theta+n \frac{F(\theta)}{f(\theta)} .
$$

The distortion increases with the number of principals. As $n$ increases, the outcome moves away from the interim efficiency frontier reached had they cooperated.

Theme 7 : Under adverse selection and public agency, although each contractual relationship is bilateral interim efficient, Nash equilibria are not interim efficient. Equilibrium contributions are not truthful.

韭 Laffont and Tirole (1993, Chapter 17) proposed an interesting application of public agency to a privatization problem. They analyzed a contractual equilibrium between a regulator and the regulated firm's equityholders who both control the firm's management. The cost of privatization is the excessive rent extraction under common agency.

Lebreton and Salanié (2003) extended the lobbying model of Grossman and Helpman (1994) by introducing uncertainty on the weight that a decision-maker gives to social welfare in his objective function given that he values also the lobbyists' contributions. They characterized equilibria for a 0-1 decision. Martimort and Semenov (2005) analyzed a lobbying game with two lobbies having ideal points located in a one-dimensional policy space. Lobbies use monetary contributions to influence a political decision-maker who is privately informed about his ideal point. ${ }^{50}$ The decision-maker is more likely to obtain some rent as the conflict of interests between the principals is exacerbated (i.e., the distance between their ideal points increases) and the shape of that rent depends both on the importance of ideological uncertainty and the degree of polarization between groups. The equilibrium policy is significantly shifted towards the agent's ideal point. An extreme form of "laissez-faire" equilibrium where the agent always chooses his ideal point and interest groups lose all influence might sometimes arise.

- Impact of Adverse Selection on Payoffs under Delegated Agency: The analysis of delegated common agency bears some similarity with that of intrinsic agency. One must nevertheless take care of the agent's type-dependent participation constraint:

$$
U(\theta)=\max _{q} T_{N}(q)-\theta q \geq \max \left\{0, \max _{\{S \subset N-\{i\}, q\}} T_{S}(q)-\theta q\right\} \quad \forall \theta \in \Theta .
$$

\footnotetext{
${ }^{50}$ There is thus horizontal differentiation between different types instead of vertical differentiation as in Lebreton and Salanié (2003).
} 
The delegated common agency game is solved in Martimort and Stole (2005a) when uncertainty on the cost parameter (i.e., $\bar{\theta}-\underline{\theta}$ ) is small enough, there are two principals and $\theta$ is uniformly distributed on $\Theta .{ }^{51}$ The set of principals' equilibrium payoffs can be characterized with simple inequalities, exactly as in the complete information model reviewed in Section 3.2. This characterization is nevertheless more complex since contributions schedules are no longer truthful. Martimort and Stole (2005a) observed indeed that the right-hand side of (29) might depend on how schedules are extended for off the equilibrium outputs. Two cases are considered:

- Natural equilibria are such that the equilibrium schedules are obtained by integrating (27) and keeping only the positive part. For a uniform distribution, this yields

$$
t_{i}(q)=\max \left\{0, \frac{1}{3}\left(2 S_{i}(q)-S_{-i}(q)+\underline{\theta} q\right)-k_{i}\right\}
$$

for some constant $k_{i}$ and for any $q$ both on and off the equilibrium. ${ }^{52}$

- Simple equilibria are such that

$$
t_{i}^{\prime}(q)=S_{i}^{\prime}(q)-(\bar{\theta}-\underline{\theta}) \quad \text { for } \quad q \leq q(\bar{\theta})
$$

Marginal contributions are thus close to the truthful ones when $\bar{\theta}-\underline{\theta}$ is small enough. Otherwise, marginal contributions schedules in both natural and simple equilibria are the same for any equilibrium output.

In the limit of a small uncertainty $(\bar{\theta}-\underline{\theta}$ converging to zero), the set of equilibrium payoffs achieved by the principals with natural and simple equilibria differ. Marginal contributions in natural equilibria keep track of the contractual externality that arises under adverse selection even when $\bar{\theta}-\underline{\theta}$ goes to zero. The value of bringing one principal in is thus lower with natural equilibria than with the truthful equilibria and that principal cannot ask for as much. The set of payoffs achieved as limits of natural equilibria is thus a strict subset of those achieved with truthful equilibria. Adverse selection becomes a selection device, albeit a crude one. ${ }^{53}$ Instead, simple equilibrium payoffs converge towards

\footnotetext{
${ }^{51}$ These assumptions ensure that the participation constraint (29) binds only for the least efficient type.

${ }^{52}$ Interestingly, marginal contributions in natural equilibria are unchanged when the cost parameter is drawn from a uniform distribution with a larger support.

${ }^{53}$ Adverse selection might sometimes be a powerful device. Take the following regulatory example (drawn from Martimort (1996b)). Two regulators offer subsidies $t_{i}(i=1,2)$ to a regulated firm which produces one unit of a good at cost $\theta$. The principals' benefits are respectively $S_{1}$ and $S_{2}$. Assume first that it is common knowledge that $\theta=\underline{\theta}$. Then, there exists a continuum of equilibria under intrinsic common agency. The principals' payoffs $\left(V_{1}, V_{2}\right)$ are such that $V_{1}+V_{2}=S_{1}+S_{2}-\underline{\theta}, V_{i} \geq 0, i=1,2$. The firm gets zero rent. Assume now that $\theta$ is distributed on $\Theta=[\underline{\theta}, \bar{\theta}]$ according to some distribution function
} 
the full set of truthful payoffs. This shows that one has to be cautious in justifying the use of nonlinear schedules under complete information by appealing to some underlying adverse selection environment. Whether the corresponding equilibrium payoffs converge towards those achieved with truthful equilibria of the complete information game or not depends on how equilibrium schedules are extended for off the equilibrium outputs even under adverse selection. To summarize, we have:

Theme 8 : The set of equilibrium payoffs of a delegated common agency game under complete information may not be robust to the choice of the off the equilibrium extensions used under adverse selection.

\subsection{Sequential Common Agency}

So far, I have focused on the case where competing principals make simultaneous offers. Let us now consider a sequential timing. To fix ideas, consider Example 1 on regulation. One may think of $P_{1}$ as being a Federal regulator acting as a Stackelberg leader whereas $P_{2}$ is a State regulator.

The sequential timing obliges to think more deeply about the principals' incentives to participate to the game. ${ }^{54}$ With sequential moves, the difficulty could be that $P_{1}$ offers transfers to the agent which are so low that inducing the agent's participation may become too costly for $P_{2}$. To avoid such issues, $P_{2}$ should have the right to shut-down the firm. This might be captured by introducing a no-veto constraint stipulating that $P_{1}$ designs his own mechanism taking into account that $P_{2}$ should not veto the firm's activity. As shown in the Appendix, the Stackelberg outcome is then defined as: ${ }^{55}$

$$
\sum_{i=1}^{2} S_{i}^{\prime}(q(\theta))=\left(\theta+\frac{F(\theta)}{f(\theta)}\left(2+\frac{d}{d \theta}\left(\frac{F(\theta)}{f(\theta)}\right)\right)\right) C^{\prime}(q(\theta)) .
$$

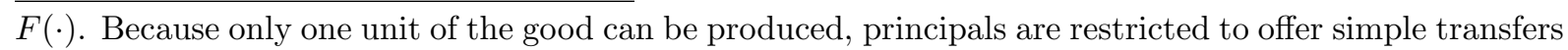
$t_{1}$ and $t_{2}$. The probability that those offers are accepted is $F\left(t_{1}+t_{2}\right)$. Principal $P_{i}$ 's expected payoff is $\left(S_{i}-t_{i}\right) F\left(t_{1}+t_{2}\right)$ whose maximum is achieved (assuming quasi-concavity of the objective which holds when the monotone hazard rate property $\frac{d}{d \theta}\left(\frac{F(\theta)}{f(\theta)}\right)>0$ is satisfied) when $S_{1}-t_{1}=S_{2}-t_{2}=\frac{F\left(t_{1}+t_{2}\right)}{f\left(t_{1}+t_{2}\right)}$. When $\bar{\theta}-\underline{\theta}$ converges to zero, a unique equilibrium survives in the complete information game which yields payoffs $V_{1}=V_{2}=\frac{S_{1}+S_{2}-\underline{\theta}}{2}$. This is the Nash-bargaining outcome had the principals decided to bargain over their respective shares of the cost of the public good.

${ }^{54}$ Implicit under simultaneous common agency is that principals obtain by contracting a payoff greater than their reservation values. This imposes some conditions on the way they can share contributions. Principals choose to participate because they earn more than by not contributing.

${ }^{55}$ This is the solution provided that it is weakly decreasing. Sufficient conditions for this are $\frac{d}{d \theta}\left(\frac{F(\theta)}{f(\theta)}\right) \geq$ 0 and $\frac{d^{2}}{d \theta^{2}}\left(\frac{F(\theta)}{f(\theta)}\right) \geq 0$. 
Compared with (28) (taken in the case $n=2$ ), output distortions are increased. To understand why that is, it is useful to think about the sequential revelation of information taking place under sequential common agency. For a given scheme $t_{1}(q)$ offered by $P_{1}$, $P_{2}$ wants to reduce the agent's output. Everything happens as if the output choice made by the implicit coalition he forms with $A$ was made with virtual costs replacing true costs because of adverse selection. Since virtual costs increases faster than true costs, the incentives of that coalition for exaggerating costs are exacerbated. When he offers his own mechanism, $P_{1}$ anticipates this effect which calls for more output distortion compared with the Nash outcome. ${ }^{56}$

Theme 9 : Under adverse selection and public agency, distortions are exacerbated with a sequential timing.

Baron (1985) was an early contribution on sequential common agency in a regulatory context where he analyzed the interaction between State and Federal regulators. Martimort (1996b) derived a formula similar to (30) in the case of a 0-1 project. Martimort (1999) developed the Stackelberg timing in the case where the agent's type can only take two values but production is continuous. Calzolari and Pavan (2005) and Kartasheva (2005) analyzed the strategic informational leakage that arises in sequential common agency games when the decision taken by the agent for one principal might be observed by followers before they offer themselves contracts. These models merge the difficulties of both the common agency and the limited commitment literatures.

\section{$5 \quad$ Informed Principals}

The justifications for the use of menus have so far relied on adverse selection on the agent's side. In this section, I instead analyze the case where principals are privately informed. A principal may now use menus both to signal his type but also to learn about those of others. An important issue is thus to understand how the principals' information is aggregated. This is particularly relevant for Example 2 since lobbying groups do not only directly influence the agent but also want to convey information.

\footnotetext{
${ }^{56}$ The intuition given above implicitly refers to a direct revelation of information. In fact, there is no problem in using a sequential version of the standard Revelation Principle here. Although $P_{1}$ does not directly contract with $P_{2}$, he still anticipates the behavior of the coalition between $P_{2}$ and $A$ exactly as if $P_{1}$ was contracting with $P_{2}$ who would then sub-contract with $A$. This analogy between sequential common agency games and hierarchical contracting is developed further in Section 6.1 below.
} 
When principals are privately informed, the model combines the difficulties of both the informed principal and the common agency literatures. Two sets of issue should be addressed. The first ones are related to the characterization of equilibria with a focus on their multiplicity and the properties of output distortions. The second ones are more normative. Are these equilibria interim efficient and, if yes, under which circumstances?

To fix ideas, consider two principals having the following preferences for a public good:

$$
V_{i}=\beta_{i} q-t_{i} \quad \text { for } \quad i=1,2 .
$$

The preference parameters $\left(\beta_{i}\right)_{i \in\{1,2\}}$ are independently and identically distributed on $B=[\underline{\beta}, \bar{\beta}]$ according to the distribution $G(\cdot)$ (density $g(\cdot))$. This public good is produced by an agent who has no private information.

Martimort and Moreira (2005) looked for symmetric Bayesian equilibria where principals choose a nonlinear contribution within a menu $\{t(q, \hat{\beta})\}_{\hat{\beta} \in B} .{ }^{57}$ The techniques used to compute these symmetric equilibria are reminiscent of those available to compute optimal strategies in first-price auctions. New difficulties stem from both the multiunit nature of bidding and the non-excludability of the public good.

In this Bayesian context, the principals' incentive compatibility constraints become:

$$
\beta_{i} \in \arg \max _{\hat{\beta}_{i}} \underset{\beta_{-i}}{E}\left(\beta_{i} q\left(\hat{\beta}_{i}, \beta_{-i}\right)-t\left(q\left(\hat{\beta}_{i}, \beta_{-i}\right), \hat{\beta}_{i}\right)\right)
$$

where the level of public good optimally chosen by the agent is given by

$$
q\left(\hat{\beta}_{1}, \hat{\beta}_{2}\right) \in \arg \max _{q} \sum_{i=1}^{2} t\left(q, \hat{\beta}_{i}\right)-\theta C(q)
$$

and the nonlinear contribution $\{t(q, \hat{\beta})\}_{\hat{\beta} \in B}$ satisfies the agent's participation constraint ${ }^{58}$

$$
U\left(\theta, \hat{\beta}_{1}, \hat{\beta}_{2}\right)=\max _{q} \sum_{i=1}^{2} t\left(q, \hat{\beta}_{i}\right)-\theta C(q) \geq 0 .
$$

The contribution $t\left(q, \hat{\beta}_{i}\right)$ selected by $P_{i}$ within the given menu is observed by the agent. When the equilibrium is fully separating, the agent is thus informed on the principals' types at the time of choosing how much to produce. This explains the form taken by his output choice (33) and his participation decision (34).

\footnotetext{
${ }^{57}$ From Epstein and Peters (1999), we know that that "market information" may matter in a common agency environment. One may wonder if the space of menus of nonlinear prices is not unnecessarily restricted. We will comment on this issue below.

${ }^{58}$ To simplify presentation, this constraint is written in the case of intrinsic common agency. Martimort and Moreira (2005) treated also the case of delegated common agency.
} 
Martimort and Moreira (2005) showed that, provided one focuses on non-decreasing equilibrium allocations, the following pointwise optimality conditions characterize an interesting class of differentiable equilibria:

$$
\beta_{i}+\frac{\partial t}{\partial q}\left(q\left(\beta_{1}, \beta_{2}\right), \beta_{-i}\right)-\theta C^{\prime}\left(q\left(\beta_{1}, \beta_{2}\right)\right)=\frac{1-G\left(\beta_{-i}\right)}{g\left(\beta_{-i}\right)} \frac{\partial^{2} t}{\partial q \partial \beta_{-i}}\left(q\left(\beta_{1}, \beta_{2}\right), \beta_{-i}\right) .
$$

These conditions capture again the fact that contracts are bilateral interim efficient.

To better understand those conditions, consider an agent having an indirect utility function defined over $\left(q, t_{i}\right)$ pairs as $t_{i}+t\left(q, \beta_{-i}\right)-\theta C(q)$ and suppose that this agent is privately informed on $\beta_{-i}$. Provided that the Spence-Mirrlees condition $\frac{\partial^{2} t}{\partial q \partial \beta_{-i}}>0$ holds, standard mechanism design techniques can be used to find the optimal contract that $P_{i}$ (who is uninformed on the parameter $\beta_{-i}$ ) offers to such an agent. To compute this optimal contract, note that there is no loss of generality for $P_{i}$ in using a direct revelation mechanism which induces the agent to reveal $\beta_{-i}{ }^{59}$ Moreover, in a private values environment with risk-neutrality, a given principal does not lose anything by revealing his type to the agent at the offer stage. ${ }^{60}$ Everything happens as if the agent's endogenous information on $P_{-i}$ 's type had to be screened by $P_{i}$.

Instead of offering a direct revelation mechanism, $P_{i}$ could as well have offered the nonlinear contribution $t\left(q, \beta_{i}\right)$ that is constructed from this direct revelation mechanism. There is thus no loss of generality in a priori restricting $P_{i}$ to choose a best-response to the nonlinear price $t\left(q, \beta_{-i}\right)$ selected by $P_{-i}$ within the menu of nonlinear contributions $\{t(q, \hat{\beta})\}_{\hat{\beta} \in B}$. More complex mechanisms would not improve $P_{i}$ 's payoff when pointwise optimality holds. "Market information" à la Epstein and Peters (1999) has thus a nice and simple interpretation in our context: this is what has been learned by the agent from observing the other principal's offer.

Since the agent withdraws some costly information rent from learning $\beta_{-i}, P_{i}$ designs a best-response which induces less output in order to reduce this rent. Equilibrium outputs are downward distorted below the first-best and each principal offers a contribution which is, at the margin, less than his own marginal valuation. ${ }^{61}$ Note that $P_{i}$ 's incentives to reduce output depend on the cross-derivative $\frac{\partial^{2} t}{\partial q \partial \beta_{-i}}$. Output distortions are greater at

\footnotetext{
${ }^{59}$ Here, we use the Revelation Principle to compute a best-response as in Section 2.

${ }^{60}$ See Maskin and Tirole (1990).

${ }^{61}$ Note that this screening motive for downward distortions is somewhat different from the usual "freeriding" problem in centralized mechanisms à la Mailath and Postlewaite (1990). There, output is reduced by an uninformed mediator who offers a centralized mechanism to reduce the agents' incentives to underestimate their own marginal valuations.
} 
a best-response if the other principal offers himself a schedule which, at the margin, depends strongly on his type. This in turn makes $P_{i}$ 's marginal contribution steeper which generates a multiplicity of equilibria.

Assuming that $G(\cdot)$ has a linear hazard rate, Martimort and Moreira (2005) showed that there exist interim efficient equilibria with marginal contributions which are linear in types. Because the agent obtains some rent by endogenously learning private information, the equilibrium outcome can only be replicated by a centralized mechanism offered by an uninformed planner if this planner gives a positive weight to the agent in his objective function. In the case of a 0-1 project, Laussel and Palfrey (2003) obtained also positive results on interim efficiency. The interim efficiency property of the common agency equilibria is surprising. Indeed, common agency differs from centralized contracting since the agent cannot commit and optimally reacts to earlier moves of the principals whereas the uninformed mediator is endowed with such commitment under centralized contracting.

Theme 10 : Assume principals are privately informed, Bayesian-Nash equilibria are ex post inefficient but they might sometimes be interim efficient.

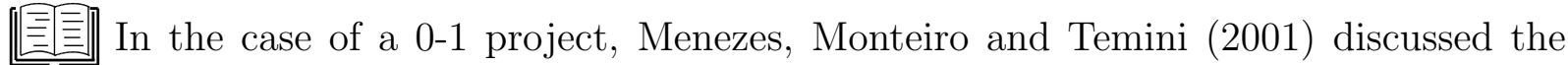
multiplicity and the ex post inefficiency of equilibria. Bond and Gresik (1997) studied the case where only one principal has private information and principals compete with piecerate contracts. There exists then an open set of inefficient equilibria. Bond and Gresik (1998) analyzed competition between tax authorities for the revenue of a multinational firm when only one of these principals knows the firm's cost parameter. Biglaiser and Mezzetti (2000) developed a model of privately informed principals competing for the services of an agent who his privately informed on his disutility of effort. Effort distortions are lower than with a single principal.

\section{Justifications of Common Agency}

One lesson of most of the previous sections is that transaction costs generally arise under multi-contracting. Equilibria most often fail to be (interim) efficient. This is somewhat puzzling given that multi-contracting prevails in organizations be they public (governments) or private (markets). A natural question is then whether multi-contracting outcomes could also be achieved under centralized contracting provided that centralized con- 
tracting is subject to some extra constraints. In other words, I now investigate whether common agency performs well in third-best environments. Two different perspectives are taken. The first one (Section 6.1) draws a link between common agency and the literature on hierarchical contracting. I show that (sequential) common agency may sometimes implement the optimal centralized contracting outcome under the threat of collusion between agents. The second approach (Section 6.2) simply compares common agency and centralized contracting in specific third-best contexts plagued with contractual problems due to either collusion or limited commitment.

\subsection{From Vertical Hierarchies to Common Agency}

Consider a three-agent organization with a principal $P$, his privately informed agent $A$, and a supervisor $S$ who is only interested in his wage $s_{2} \cdot{ }^{62}$ The principal's, the supervisor's and the agent's utility functions are respectively: ${ }^{63}$

$$
V_{1}=S(q)-t_{1}-s_{2}, \quad V_{2}=s_{2} \quad \text { and } \quad U=t_{1}-\theta C(q)
$$

The supervisor bridges the information gap between the principal and the agent by receiving a soft information signal $\sigma \in\left\{\sigma_{1}, \sigma_{2}\right\}$ (with respective probabilities $p$ and $1-p$ ) on the agent's type. This signal is observed by both $S$ and $A$. Following the observation of $\sigma_{i}$, the agent's type is believed to be drawn from the cumulative distribution $F_{i}(\theta)$. The monotone hazard rate properties $\frac{d}{d \theta}\left(\frac{F_{i}(\theta)}{f_{i}(\theta)}\right)>0(i=1,2)$ hold as well as the following ranking between conditional hazard rates: $\frac{F_{1}(\theta)}{f_{1}(\theta)} \geq \frac{F_{2}(\theta)}{f_{2}(\theta)}$.

- Benchmark: Suppose that the principal learns directly $\sigma_{i}$. Second-best output distortions depend on the realized signal. The principal recommends an output $q^{S B}\left(\theta, \sigma_{i}\right)$ and leaves a rent $U^{S B}\left(\theta, \sigma_{i}\right)$ to the agent where:

$$
S^{\prime}\left(q^{S B}\left(\theta, \sigma_{i}\right)\right)=\left(\theta+\frac{F_{i}(\theta)}{f_{i}(\theta)}\right) C^{\prime}\left(q^{S B}\left(\theta, \sigma_{i}\right)\right) \quad \text { and } \quad U^{S B}\left(\theta, \sigma_{i}\right)=\int_{\theta}^{\bar{\theta}} C\left(q^{S B}\left(x, \sigma_{i}\right)\right) d x \text {. }
$$

Note that $\sigma_{1}$ (resp. $\sigma_{2}$ ) is good (resp. bad) news on the type distribution, and it is associated with large (resp. small) distortions.

- Supervision: Consider now a centralized organization where $P$ offers to both $S$ and $A$ the wages $\left\{s_{2}\left(q, \hat{\sigma}_{i}\right), t_{1}\left(q, \hat{\sigma}_{i}\right)\right\}$ linking their compensations to the signal $\hat{\sigma}_{i}$ reported by

\footnotetext{
${ }^{62}$ Tirole (1986, 1992), Faure-Grimaud, Laffont and Martimort (2002, 2003), and Baliga and Sjoström (1998) (among others) present various models of hierarchical supervision.

${ }^{63}$ Outside opportunities are normalized at zero.
} 
the supervisor to the principal and to the output chosen by the agent.

A benevolent supervisor reports his signal to the principal (i.e., $\hat{\sigma}_{i}=\sigma_{i}$ ) and does not need to be paid for doing so. The solution is again described by (36). Because output distortions are greater following $\sigma_{1}$, the agent obtains more rent if $\sigma_{2}$ is reported to the principal. This creates a priori some scope for collusion between $S$ and $A .{ }^{64}$ My goal here is not to derive the whole class of collusion-proof incentive mechanisms. I shall first notice that an upper bound on what can be achieved by $P$ is precisely given by (36) (i.e., the outcome in the absence of collusion) and then I shall show that sequential common agency achieves this outcome.

Suppose indeed that $P$ only contracts with $S$ who then contracts with $A$. With such delegation, the principal uses de facto an explicit collusion between $S$ and $A$ on the equilibrium path. Assume that the supervisor has no veto rights and accepts contracting ex ante, i.e., before knowing signal $\sigma$ and learning the agent's cost parameter. Consider then the simple "sell-out" contract: $\tilde{s}_{2}^{i}(q)=S(q)-k^{*}$ where $k^{*}$ is a constant whose value will be determined below. This scheme does not depend of the supervisor's information. However, following acceptance of this mechanism, the supervisor uses his knowledge of $\sigma_{i}$ to implement the second-best outputs and rents $\left\{q^{S B}\left(\theta, \sigma_{i}\right), U^{S B}\left(\theta, \sigma_{i}\right)\right\}$ by offering a wage $y\left(q, \sigma_{i}\right)$ to the agent. ${ }^{65,66}$

Suppose now that $P$ can only contract with $A$ before $S$ comes in and contracts himself with $A$. The setting is much alike that of the sequential common agency game in Section 4.4 with the only differences being that $S$ who acts as a follower has no veto rights and

\footnotetext{
${ }^{64}$ Suppose that the supervisor knows not only the realized signal $\sigma_{i}$ but also the agent's cost parameter. There is then complete information between $S$ and $A$. Because the signal affects neither the agent nor the supervisor's payoff and is soft, there is no way for the principal to learn about it. This is nothing else than the result that supervisory information is generally not valuable when it is soft and collusion between the supervisor and the agent takes place under complete information (see Tirole (1986) and Baliga (1999) on this topic). The optimal contract robust to collusion would pool over $\sigma_{i}$ and implement an output $q^{P}(\theta)$ and a rent profile $U^{P}(\theta)$ independent of $\sigma_{i}: S^{\prime}\left(q^{P}(\theta)\right)=\left(\theta+\frac{F(\theta)}{f(\theta)}\right) C^{\prime}\left(q^{P}(\theta)\right)$ and $\left.U^{P}(\theta)\right)=$ $\int_{\theta}^{\bar{\theta}} C^{\prime}\left(q^{P}(x) d x\right.$. where $F(\theta)=p F_{1}(\theta)+(1-p) F_{2}(\theta)$ and $f(\theta)=p f_{1}(\theta)+(1-p) f_{2}(\theta)$. This outcome can of course be implemented by contracting only with the agent.

${ }^{65}$ Formally, we have $y\left(q, \sigma_{i}\right)=\theta^{S B}\left(q, \sigma_{i}\right) C(q)+U^{S B}\left(\theta^{S B}\left(q, \sigma_{i}\right), \sigma_{i}\right)$ where $\theta^{S B}\left(q, \sigma_{i}\right)$ is the inverse function of $q^{S B}\left(\theta, \sigma_{i}\right)$ defined on (36). The fee $k^{*}$ is chosen by $P$ to extract $S$ 's expected surplus

$$
k^{*}=E_{\sigma}\left(\int_{\Theta}\left(S\left(q^{S B}\left(\theta, \sigma_{i}\right)\right)-\left(\theta+\frac{F_{i}(\theta)}{f_{i}(\theta)}\right) C\left(q^{S B}\left(\theta, \sigma_{i}\right)\right)\right) f_{i}(\theta) d \theta\right)
$$

where $E_{\sigma}(\cdot)$ is the expectation operator with respect to $\sigma$.

${ }^{66}$ Although supervisory information is soft, it becomes now useful. The principal benefits from the fact that there is still asymmetric information on $\theta$ between $S$ and $A$ to delegate at no cost the control of the agent to the intermediate level.
} 
is privately informed about the type distribution. $P$ can still achieve the second-best outcome by offering $\tilde{s}_{2}^{i}(q)$ to $A$ and having $S$ receive $s_{2}\left(q, \sigma_{i}\right)=\tilde{s}_{2}^{i}(q)-y\left(q, \sigma_{i}\right)$ from $A$. With this scheme the supervisor induces the second-best outputs and is just indifferent between participating or not. He brings nevertheless his expertise to the organization because outputs now depend on $\sigma_{i}$. Ultimately, this benefit accrues to the principal. Splitting contracting between the uninformed principal and the informed supervisor but keeping a Stackelberg timing gives an implementation of the second-best which is de facto collusion-proof.

Such organization raises nevertheless two issues. First, the supervisor suffers a loss from allowing the inefficient type to produce since he can only break even in expectation. If the supervisor had veto rights, he would shut-down production of that type. Second, this organization does not give $S$ enough incentives for gathering information. ${ }^{67}$ The solution to both problems is to leave veto rights to $S$ so that he gets an information rent related to his knowledge of supervisory information. This rent may then be large enough to induce information gathering. In that case, even though new distortions are associated to common agency, having two principals might still be useful.

Theme 11 : Sequential common agency may implement the centralized second-best outcome in a collusion-proof way if the informed principal acting as a follower has no veto rights. Otherwise, it implements a third-best outcome but might still be useful.

This section has briefly touched on two important trends of the recent literature which are somewhat related, namely collusion in multi-agent organizations and hierarchical contracting. My purpose here is not to survey these topics but to give a bit of perspective to better understand what has been done above.

- Collusion: Laffont and Martimort (1997) modelled collusion under asymmetric information in multi-agent organizations. An uninformed third-party organizes a sidemechanism to facilitate collusion. This side-mechanism gives to the agents more than their reservation payoffs had they played non-cooperatively the principal's grand-mechanism. It must also be incentive compatible because of asymmetric information within the coali-

\footnotetext{
${ }^{67}$ Suppose indeed that $S$ must undertake a non-verifiable effort in gathering information prior any contracting. If $S$ has no veto rights, he is under the threat of the principal's opportunistic behavior who offers a contract which indirectly does not reward the supervisor for information gathering. As a result, no information gathering takes place.
} 
tion. ${ }^{68}$ The optimal collusion-proof anonymous mechanism was derived in the case of two agents producing complementary inputs for the organization and having marginal costs which are independently distributed. Non-anonymous dominant strategy mechanisms may still achieve the second-best collusion-free outcome even under the threat of collusion. More generally, Laffont and Martimort (2000) showed that there exists a Bayesian mechanism which always implements the second-best outcome even under the threat of collusion if types are not correlated. We also provided a Collusion-Proofness Principle under asymmetric information. Collusion-proof optimal contracts were then characterized even when types are correlated. Yardstick mechanisms which are known to fully extract the agents' rents if types are correlated and agents do not collude ${ }^{69}$ are of little help with collusion. This is precisely when the principal benefits the most from the agents' competition that their incentives to collude are also the strongest. ${ }^{70}$ In a hierarchical model of supervision, Faure-Grimaud, Laffont, and Martimort (2003) showed that delegating control of the agent to the supervisor may still be useful even if the latter is risk-averse. An equivalence exists between a centralized organization designed by the principal under the threat of collusion and a nexus of vertical contracts involving the principal and the supervisor on one side and the supervisor and the agent on the other. However, risk-aversion implies that delegation is costly. ${ }^{71}$ As in our example above, supervisory information is useful even when it is soft and collusion is an issue.

-Vertical Hierarchies: This implementation of the collusion-proof allocation through delegation brings us to the mechanism design approach of hierarchies. ${ }^{72}$ In a model with two productive agents who are privately informed on their respective marginal costs, Melumad, Mookherjee and Reichelstein (1995) argued that delegation achieves the same

\footnotetext{
${ }^{68}$ Quesada (2004) analyzed the case where an informed agent designs the mechanism for his colluding partner and argued that optimal mechanisms may be asymmetric in such contexts.

${ }^{69}$ See Crémer and McLean (1988).

${ }^{70}$ Considering the possibility of collusion also establishes some continuity between the contracting outcomes under independent and correlated information, something that is known not to hold under pure Bayesian-Nash behavior. Che and Kim (2005) pointed out that this continuity is lost when there are at least three agents and that a simple "sell-out" mechanism making the third-party residual claimant achieves the no-collusion outcome. Jeon (2005) obtained a similar result in the case of two agents only but collusion is then hindered by the fact that agents are protected by limited liability. Dequiedt (2004) showed that collusion may be much more harmful to an organization if the collusive agreement takes place before acceptance of the grand-mechanism. Pavlov (2004) extended also the Laffont and Martimort (1997, 2000) framework to the case of a continuum of types and to the case where the third-party organizing the collusion may have redistributive concerns. He showed that simple mechanisms may sometimes fight collusion at no cost even if collusion can coordinate the agents' decisions to participate.

${ }^{71}$ For another model justifying delegation as an optimal response to collusion see Baliga and Sjoström (1998). By using a different information structure, Celik (2004) demonstrated that a centralized organization may be preferred if it creates countervailing incentives within the coalition.

${ }^{72}$ See Mookherkee (2005) for a review.
} 
outcome as a more centralized organization where the principal directly contracts with both agents. ${ }^{73}$ This is no surprise in view of our previous discussion. Delegation relies explicitly on collusion on the equilibrium path, but we know that collusion does not harm the organization in the informational environment analyzed by these authors. Key to Melumad, Mookherjee and Reichelstein (1995) is the fact that the intermediate principal accepts contracts before learning information from lower levels of the hierarchies. ${ }^{74}$ This contrasts with McAfee and Millan (1995) who instead analyzed hierarchical contracting when successive principals are protected by ex post participation constraints. Information rents add up along the hierarchy. A similar effect arises with the no-veto constraints in the model I sketched above. ${ }^{75}$ Laffont and Martimort (1998) showed that delegation may dominate centralization when the latter suffers from collusion.

\subsection{Collusion, Limited Commitment and Common Agency}

Section 4.3 already showed that splitting the control of the agent among several principals under public agency leads to excessive rent extraction and to greater distortions compared with centralized contracting. Although those excessively low powered incentives may appear as a cost compared with centralized contracting, they may be useful in contexts where high powered incentives create contractual hazards. I analyze two such environments of interests, both motivated by regulation which offers an archetypical example to explain the separation between different governing bodies.

- Collusion: Consider Example 1 but suppose now that regulators are somewhat biased in favor of the regulated firm. The capture of the decision-maker by the regulated firm might be modelled in an ad hoc manner by assuming that each principal gives to the firm a positive weight $\alpha$ (but $\alpha<1^{76}$ ) in his objective function. With constant marginal cost,

\footnotetext{
${ }^{73}$ Baron and Besanko (1992) and Gilbert and Riordan (1995) compared also the decentralized organization with a consolidation where agents merge. The latter organization dominates under weak conditions. Baron and Besanko (1999) and Dequiedt and Martimort (2004) analyzed the agents' incentives to merge when it is costly (either because agents must get more utility than by remaining split apart in Baron and Besanko (1999) or because agents must incur a fixed cost to learn each other's types in Dequiedt and Martimort (2004)). Mookherjee and Tsugamari (2004) performed more general comparisons between the consolidated, the centralized and the decentralized organizations depending on the degree of complementarity between the agents' inputs.

${ }^{74}$ See also Mookherjee and Reichelstein (2001) for a generalization to more complex organizations. An earlier vintage of that idea could be found in Crémer and Riordan (1987) who analyzed a model where only ex ante contracting is feasible.

${ }^{75}$ Faure-Grimaud and Martimort (2001) analyzed this no-veto constraint in a model with an uninformed and risk-averse intermediary.

${ }^{76}$ This assumption ensures that the information rent of the firm is viewed as costly by each principal.
} 
the equilibrium output becomes now:

$$
\sum_{i=1}^{n} S_{i}^{\prime}(q(\theta))=\theta+n(1-\alpha) \frac{F(\theta)}{f(\theta)} .
$$

Two effects are at work simultaneously. On the one hand, having biased principals goes in the direction of giving too high-powered incentives to the firm. On the other hand, those distorted incentives are somewhat countered by the principals' non-cooperative behavior. From a social welfare viewpoint, ${ }^{77}$ it may then be optimal to split tasks between biased regulators to come closer to the socially optimal distortion. ${ }^{78}$

位 In the model above, no explicit incentive scheme is used to correct the behavior of biased principals. Separation of powers is thus a substitute for these missing incentives. Along these lines, Laffont and Pouyet (2003) observed that regulation is subject to political risk and changes as different majorities alternate in office. However, when markets are opened and firms operate in several regulatory environments at the same time, regulatory competition induces very high-powered incentive schemes independently of the identity of national regulators. Market openness insulates the firm from national pressure.

From a theoretical viewpoint, it may be interesting to ask whether this separation of powers can be justified in a full-fledged model where the regulators' biases can be corrected by an incentive scheme. Doing so requires to give up the common agency model and adopt a three-tier model of regulatory capture à la Laffont and Tirole (1993, Chapter 11). This model justifies the presence of the regulator as a way to bridge an informational gap between the privately informed regulated firm and the rest of society. It helps tracing out the consequences of the threat of capture on optimal regulation. A regulator has power because he learns some piece of information that is relevant for the firm. By not using this piece of information to improve welfare, the regulator may enjoy a share of the firm's information rent. Ensuring collusion-proofness comes at a cost for society. In response to the threat of capture, regulators should thus follow more bureaucratic rules leaving little scope for discretion and implementing low-powered incentives for regulated firms. Laffont and Martimort (1999) asked whether separating powers between two regulators can reduce the cost of ensuring collusion-proofness and improve welfare. Two regulators may each learn one piece of information relevant to extract the firm's information rent. ${ }^{79}$ It may turn out that both signals provide information rent to the firm; the collusive deal between

\footnotetext{
${ }^{77}$ The implicit definition of social welfare used here is: $W=\sum_{i=1}^{n} S_{i}(q)-\theta q-U$.

${ }^{78} \mathrm{~A}$ sufficient condition would be $n(1-\alpha)<1$.

${ }^{79}$ For instance, the firm's marginal cost parameter is the sum of two independent components, each of them being observed with some probability by a regulator.
} 
a single regulator informed on both signals and the firm is thus quite efficient and the cost of ensuring collusion-proofness becomes quite large. With two regulators, the collusive deal between each of them and the firm takes place under asymmetric information on what the other has observed. This may induce each regulator to adopt a prudent behavior and reduce the bribes he requests from the firm. The cost of ensuring collusion-proofness decreases and welfare is improved under separation. Although the argument in Laffont and Martimort (1999) does not rely on whether the signals observed by the regulators are correlated or not, correlation reinforces the benefits of separation by instilling a dose of yardstick competition as in Laffont and Meleu (2001). Mishra and Anant (2004) built on Laffont and Martimort (1999) and studied the incentives of a regulatory body to extend its power towards other agencies' juridictions. Hiriart, Martimort and Pouyet (2005) analyzed the benefits of separating ex ante and ex post regulators in a sequential model.

- Limited Commitment: Let us think about a centralized contracting framework extended over two periods, but assume now that the principal has a limited ability to commit. Contracts can either be short-term and cover only the current period or longterm but renegotiated as the principal learns new information from observing the agent's past performances. ${ }^{80}$ With short-term contracting, information is only gradually revealed over time. An efficient agent is reluctant to reveal his type in the first period because he fears that the principal will use this information to extract his future rent. Because of this so-called ratchet effect, the usual trade-off between efficiency and rent extraction is hardened under non-commitment. One way to mitigate this effect is to offer high powered incentives in the first period so that early revelation becomes more attractive to an efficient agent. Common agency offers another instrument to improve information revelation as shown by Olsen and Torsvick (1993). Under common agency, there is too much rent extraction in the second period of the relationship. This makes it less attractive for an efficient firm to hide its type in the first period. This reduces the likelihood of first-period pooling, and increases the scope for semi-separating allocations.

进恶Although splitting regulatory powers among several principals improves information revelation, it comes also at a cost in the earlier periods of the relationships. Olsen and Torsvick (1995) analyzed the optimal number of principals that results from this trade-off.

Under centralized contracting, the benefits of renegotiating long-term contracts comes

\footnotetext{
${ }^{80}$ For analysis of those two contractual settings, see respectively Laffont and Tirole (1993, Chapters 9 and 10) and the references therein.
} 
from the increased efficiency at the renegotiation stage. The cost stems from the fact that an efficient agent is unlikely to reveal his type in the first period to enjoy the greater rent that this second period renegotiated contract would bring. Renegotiation hardens again the rent-efficiency trade-off. Martimort (1999) stressed also the benefits of separation under renegotiation. Common agency ${ }^{81}$ makes renegotiation less efficient and thus improves the collective ability to commit.

\section{Concluding Remarks}

Multi-contracting mechanism design offers a number of challenges for Incentive Theory. Those challenges certainly deserve further research both on the theory side but also in terms of the relevance for applications. Let me mention a few alleys where progress would be welcome, going from the most theoretical ones to applications.

First, as discussed earlier, the characterization of incentive feasible allocations implemented as contract equilibria requires new tools which need to be better understood and studied in more general contexts than those highlighted in this paper. In particular, multiprincipal-multiagents games may raise new fascinating issues. The first issue concerns what kind of Revelation/Taxation Principle can be used in this context. ${ }^{82}$ The second issue is related to the multiplicity problem. The mechanisms non-cooperatively offered by competing principals define a game played by agents and, following the implementation literature developed under centralized contracting, ${ }^{83}$ one may be concerned with the multiplicity of equilibria of this game. Principals might disagree on the most preferred continuation equilibrium and there is no reason to give any of them the right to choose that continuation. In such contexts, principals might adopt prudent behavior and design mechanisms with an eye on the worst continuation equilibria that they may face.

Second, common agency games are generally plagued by a multiplicity of equilibria due to the lack of coordination among principals. As I suggested above, embedding these models in more complex informational environments might sometimes help selecting among those equilibria. The lack of robustness of some of the results to fine details of

\footnotetext{
${ }^{81}$ Actually the model is one with sequential common agency.

${ }^{82}$ The role of menus in multiprincipals/multiagents games has been recently analyzed in Han (2004) who generalized Peters (2003) to the case of several agents. Yamashita (2005) extended also the Revelation Principle to those contexts by requiring that an agent reports not only his type but also which outcome is realized.

${ }^{83}$ See Moore (1992) and Palfrey (1992).
} 
the information structure might then become troublesome if one wants to head towards a theory of robust contracting. More work should be devoted to the selection issue. In some contexts, and I think here mostly to applications for political science, convergence towards a particular equilibrium may follow learning procedures or may result of historical events which should be explicitly modelled.

Third, the fact that equilibrium outcomes generally fail to be (interim) efficient suggests that the transaction costs that arise in multi-contracting environments need to be better understood. One way to address this issue which has been only briefly touched upon in this survey consists in looking at those common agency games as implementation of more centralized mechanisms constrained in some way. The benefits of restoring a role for centralized mechanisms is twofold. First, it would eliminate the multiplicity problem due to coordination failures among principals. Second, it would allow to rely on optimization to characterize constrained-optimal mechanisms. In my view, this theoretical step is key to understand the the forces favoring multi-contracting practices. ${ }^{84}$

On a more applied stance, let me come back on some of the examples stressed in that survey to highlight a few possible avenues.

Models of regulation by multiple governing bodies should be adapted to better understand how agencies interact and compete to gain power. Most often, the missions of an agency are vaguely defined once it is enacted. As a result of this incompleteness, there is a continuous struggle among agencies and the set of contracting variables over which they have respectively control should be endogenized in some ways.

Still in the field of political science, models of influence by competing lobbies should be extended by adding private information either on the interest groups' or on the decisionmaker's side. Taking into account the corresponding transaction costs may help to better understand various patterns of contributions and influence found in practice. ${ }^{85}$

A serious weakness of the common agency literature when it applies to political science is that existing models rely too much on monetary incentives. A typical example would be the relationship between heterogenous voters and politicians concerned with their reelection. More generally, more work should be devoted to understanding contractual

\footnotetext{
${ }^{84}$ One way of restoring some role for centralized contracting is suggested by Martimort and Stole (2005b) who showed that equilibria of a public common agency game under asymmetric information may be replicated as solutions of a collective problem.

${ }^{85}$ For some steps in this direction, see Martimort and Semenov (2005).
} 
externalities in environments where monetary incentives are not available. ${ }^{86}$

Finally, in the I.O. literature, a better understanding of manufacturers/retailers structures certainly requires to develop models involving multiple principals and multiple agents interacting on the market place. Again, progresses on those issues might be obtained by studying some specific examples.

All those extensions are still awaited to offer a more complete view of multi-contracting. This view is necessary if we want to reconcile Incentive Theory with the concerns of social scientists from other fields.

University of Toulouse, 21 Allée de Brienne, 31000 Toulouse, France; and Institut Universitaire de France; Email: martimor@cict.fr.

${ }^{86}$ I thank Thomas Palfrey for pointing that to me in his discussion at the World Congress. 


\section{Appendix}

- Sequential Common Agency: Given the nonlinear schedule $t_{1}(q)$ offered by $P_{1}$ to $A$, optimal contracting between $P_{2}$ and $A$ leads to choose an output which, according to (26), solves:

$$
S_{2}^{\prime}(q(\theta))+t_{1}^{\prime}(q(\theta))=\left(\theta+\frac{F(\theta)}{f(\theta)}\right) C^{\prime}(q(\theta)) .
$$

Define now $P_{2}$ 's payoff for each realization of $\theta$ as

$$
V_{2}(\theta)=\max _{q} S_{2}(q)+t_{1}(q)-\left(\theta+\frac{F(\theta)}{f(\theta)}\right) C(q) .
$$

Using the Envelope Theorem, we get:

$$
\dot{V}_{2}(\theta)=-\left(1+\frac{d}{d \theta}\left(\frac{F(\theta)}{f(\theta)}\right)\right) C^{\prime}(q(\theta)) .
$$

Using revealed preferences arguments and (39) yields the monotonicity condition

$$
\dot{q}(\theta) \leq 0
$$

Because $P_{2}$ has veto rights, he could decide to shut-down the production of an agent with type $\theta$ if the net benefit of having that type produce is negative. To avoid shut-down, the following no-veto constraint must thus hold:

$$
V_{2}(\theta) \geq 0
$$

Acting as a Stackelberg leader, $P_{1}$ anticipates this continuation of the contracting game and solves:

$$
\begin{gathered}
\left(\mathcal{P}_{1}^{S}\right): \max _{\left\{q(\cdot), V_{2}(\cdot)\right\}} \int_{\Theta}\left(\sum_{i=1}^{2} S_{i}(q(\theta))-\left(\theta+\frac{F(\theta)}{f(\theta)}\right) C(q(\theta))-V_{2}(\theta)\right) f(\theta) d \theta \\
\text { subject to (40) to }(42) .
\end{gathered}
$$

From (40) and the fact that (42) binds at $\bar{\theta}$ only, we get:

$$
V_{2}(\theta)=\int_{\theta}^{\bar{\theta}}\left(1+\frac{d}{d x}\left(\frac{F(x)}{f(x)}\right)\right) C^{\prime}(q(x)) d x .
$$

Integrating by parts and inserting into the maximand above and optimizing pointwise leads to (30). This output schedule is decreasing if $\frac{d}{d \theta}\left(\frac{F(\theta)}{f(\theta)}\right) \geq 0$ and $\frac{d^{2}}{d \theta^{2}}\left(\frac{F(\theta)}{f(\theta)}\right) \geq 0$. Q.E.D. 


\section{References}

Attar, A., D. Majumdar, G. Piaser and N. Porteiro (2005): "Common Agency Games with Separable Preferences," mimeo Core, Bruxelles.

Baliga, S. (1999): "Monitoring and Collusion with Soft Information," Journal of Law, Economics and Organization, 15, 434-440.

Baliga, S. and T. Sjoström (1998): "Decentralization and Collusion," Journal of Economic Theory, 83, 196-232.

Baron, D. (1985): "Non-Cooperative Regulation of a Non-Localized Externality," Rand Journal of Economics, 16, 553-568.

Baron, D. and D. Besanko (1992): "Information, Control and Organizational Structure," Journal of Economics and Management Strategy, 1, 237-275.

- (1999): "Informational Alliances," Review of Economic Studies, 66, 743768.

Baron, D. and R. Myerson (1982): "Regulating a Monopolist with Unknown Costs," Econometrica, 50, 911-930.

Bergemann, D. and J. Valimaki (2003): "Dynamic Common Agency," Journal of Economic Theory, 111, 23-48.

Bernheim, D. and M. Whinston (1986a): "Common Agency," Econometrica, 54, 923-942.

— (1986b): "Menu Auctions, Resource Allocations and Economic Influence," Quarterly Journal of Economics, 101, 1-31.

Biais, B., D. Martimort and J.C. Rochet (2000): "Competing Mechanisms in a Common Value Environment," Econometrica, 68, 799-837.

Biglaiser, G. and C. Mezzetti (1993): "Principals Competing for an Agent in the Presence of Adverse Selection and Moral Hazard," Journal of Economic Theory, 61, 302-330.

- (2000): "Incentive Auctions and Information Revelation," Rand Journal of Economics, 31, 145-164.

Bond, E. and T. Gresik (1996): "Regulation of Multinational Firms with Two Active Governments: A Common Agency Approach," Journal of Public Economics, 59, 33-53. 
- (1997): "Competition between Asymmetrically Informed Principals," Economic Theory, 10, 227-240.

— (1998): "Incentive Compatible Information Transfer Between Asymmetrically Informed Principals," Mimeo University of Notre-Dame.

Calzolari, G. (2001): "The Theory and Practice of Regulation with Multinational Enterprises," Journal of Regulatory Economics, 20, 191-211.

Calzolari, G., and A. Pavan (2002): "A Markovian Revelation Principle for Common Agency Games," Mimeo Northwestern University.

- (2005): "On the Optimality of Privacy in Sequential Contracting," forthcoming Journal of Economic Theory.

Calzolari, G., and C. Scarpa (1999): "Non-Intrinsic Common Agency," ENIFEEM Nota di Lavoro 39.01.

Celik, G. (2004): "Mechanism Design with Collusive Supervision," Mimeo UBC.

Che, Y.-K. and J. Kim (2005): "Robustly Collusion-Proof Implementation," mimeo University of Wisconsin.

Crémer, J., and R. McLean (1988): "Full Extraction of Surplus in Bayesian and Dominant Strategy Auctions," Econometrica , 56, 1247-1257.

Crémer, J., and M. Riordan (1987): "On Governing Multilateral Transactions with Bilateral Contracts," Rand Journal of Economics, 18, 436-451.

D'Aspremont, C. and R. Dos Santos Ferreira (2005): "Oligopolistic Competition as a Common Agency Game," mimeo CORE.

Dasgupta, P., P. Hammond and E. Maskin (1979): "The Implementation of Social Choice Rules," Review of Economic Studies, 46, 185-216.

De Villemeur, E. and B. Versaevel (2003): "From Private to Public Agency," Journal of Economic Theory, 111, 305-309.

Dequiedt, V. (2004): "Efficient Collusion in Optimal Auctions," mimeo INRAGAEL Grenoble.

Dequiedt, V. and D. Martimort (2004): "Delegation and Consolidation: Direct Monitoring versus Arm's Length Contracting," International Journal of Industrial Organization, 22, 951-981. 
Diaw, K. and J. Pouyet (2005): "Information, Competition, and (In)complete Discrimination," mimeo Ecole Polytechnique Paris.

Dixit, A., Grossman G. and E. Helpman (1997): "Common Agency and Coordination," Journal of Political Economy, 105, 752-769.

Epstein, L. and M. Peters (1999): "A Revelation Principle for Competing Mechanisms," Journal of Economic Theory, 88, 119-160.

Faure-Grimaud, A., J.J-. Laffont and D. Martimort (2002): "Risk-Averse Supervisors and the Efficiency of Collusion," Contributions in Theoretical Economics, Vol. 2, Issue 1, Article 5.

- (2003): "Collusion, Delegation and Supervision with Soft Information," Review of Economic Studies, 70, 253-280.

Faure-Grimaud, A. and D. Martimort (2001): "The Agency Cost of Intermediated Contracting," Economics Letters, 71, 75-82.

Gal-Or, E. (1991): “A Common Agency with Incomplete Information," Rand Journal of Economics, 22, 274-286.

Gibbard, A. (1973): "Manipulation for Voting Schemes," Econometrica, 41, 617-631.

Gilbert, R. and M. Riordan (1995): "Regulating Complementary Products: A Comparative Institutional Analysis," Rand Journal of Economics, 26, 243-256.

Green, J. and J.-J. Laffont (1977): "Characterization of Satisfactory Mechanisms for the Revelation of Preferences for Public Goods," Econometrica, 45, 427-438.

Grossman, G. and E. Helpman (1994): "Protection for Sale," American Economic Review, 84, 833-850.

- (2002): Interest Groups and Trade Policy, Princeton: Princeton University Press.

Han, S. (2004): "Menu Theorems for Bilateral Contracting," Micro Theory Working Papers, University Western Ontario.

Helpman, E. (1997): "Politics and Trade Policy," in Advances in Economics and Econometrics: Theory and Applications, eds. D. Kreps and K. Wallis. Cambridge: Cambridge University Press. 
Helpman, E. and T. Persson (2001): "Lobbying and Legislative Bargaining," Advances in Economic Analysis and Policy, Vol. 1, Issue 1, Article 3. http://www.bepress.com/bejeap.

Hiriart, Y., D. Martimort and J. Pouyet (2005): "The Public Management of Environmental Risk: Separating Ex Ante and Ex Post Monitors," Mimeo IDEI Toulouse.

Holmström, B. and R. Myerson (1983): "Efficient and Durable Decision Rules with Incomplete Information," Econometrica, 51, 1799-1819.

Hurwicz, L. (1972): "On Information Decentralized Systems," in Decision and Organization (Volume in Honor of J. Marshack), eds. R. Radner and C. MCGuire. Amsterdam: North Holland.

Ivaldi, M. and D. Martimort (1994): "Competition under Nonlinear Pricing," Annales d'Economie et de Statistiques, 34, 71-114.

Jeon, D.-S. (2005): "The Failure to Collude in the Presence of Asymmetric Information," mimeo Pompeu Fabra, Barcelona.

Kartasheva, A. (2005): "Optimal Design of Investment Promotion Policies," Mimeo Georgia State University.

Khalil, F., D. Martimort and B. Parigi (2004): "Monitoring a Common Agent: Implications for Financial Contracting," forthcoming Journal of Economic Theory.

Kirchsteiger, G. and A. Prat (2001): "Inefficient Equilibria in Lobbying," Journal of Public Economics, 82, 349-375.

Klemperer, P. and M. Meyer (1989): "Supply Function Equilibria in Oligopoly under Uncertainty," Econometrica, 57, 1243-1277.

Konishi, H., M. Lebreton and S. Weber (1999): "On Coalition-Proof Nash Equilibria in Common Agency Games," Journal of Economic Theory, 85, 122-139.

Laffont, J.-J. and D. Martimort (1997): "Collusion under Asymmetric Information," Econometrica, 65, 875-912.

- (1998): "Collusion and Delegation," Rand Journal of Economics, 29, 280305. 
- (1999): "Separation of Regulators Against Collusive Behavior," Rand Journal of Economics, 107, 1089-1127.

- (2000): "Mechanism Design with Collusion and Correlation," Econometrica, 68, 309-342.

- (2002): The Theory of Incentives: The Principal-Agent Model, Princeton: Princeton University Press.

Laffont, J.-J. and M. Meleu (2001): "Separation of Powers and Economic Development," Journal of Development Economics, 64, 129-145.

Laffont, J.-J. and J. Pouyet (2003): "The Subsidiary Bias in Regulation," Journal of Public Economics, 88, 255-283.

Laffont, J.-J. and J. Tirole (1993): A Theory of Incentives in Regulation and Procurement, Cambridge: MIT Press.

Laussel, D. and M. Lebreton (1998): "Efficient Private Production of Public Goods under Common Agency," Games and Economic Behavior, 25, 194218.

- (2001): "Conflict and Cooperation: The Structure of Equilibrium Payoffs in Common Agency," Journal of Economic Theory, 100, 93-128.

Laussel, D. and T. Palfrey (2003): "Efficient Equilibria in the Voluntary Contributions Mechanisms with Private Information," Journal of Public Economic Theory, 5, 449-478.

Lebreton, M. and F. Salanié (2003): "Lobbying under Political Uncertainty," Journal of Public Economics, 87, 2589-2610.

Mailath, G. and A. Postlewaite (1990): "Asymmetric Information Bargaining Problems with Many Agents," Review of Economic Studies, 57, 351-368.

Martimort, D. (1992): "Multi-Principaux avec Anti-Selection," Annales d'Economie et de Statistiques, 28, 1-38.

— (1996a): "Exclusive Dealing, Common Agency and Multiprincipal Incentive Theory," Rand Journal of Economics, 27, 1-31.

- (1996b): "The Multiprincipal Nature of the Government," European Economic Review, 40, 673-685. 
— (1999): "Renegotiation Design with Multiple Regulators," Journal of Economic Theory, 88, 261-293.

Martimort, D. and H. Moreira (2005): "Common Agency with Informed Principals," Mimeo IDEI Toulouse.

Martimort, D. and A. Semenov (2005): "How Does Ideological Uncertainty Affect Lobbying Competition: A Common Agency Perspective," Mimeo IDEI Toulouse.

Martimort, D. and L. Stole (2002): "The Revelation and Delegation Principles in Common Agency Games," Econometrica, 70, 1659-1674.

- (2003a): "Contractual Externalities and Common Agency Equilibria," Advances in Theoretical Economics, Vol. 3, Issue 1, Article 4.

http://www.bepress.com/bejte.

- (2003b): "Market Participation under Delegated and Intrinsic Common Agency Games," Mimeo University of Chicago and IDEI Toulouse.

- (2005a): "On the Robustness of Truthful Equilibria in Common Agency Games," Mimeo IDEI and University of Chicago.

— (2005b): "Common Agency Games with Common Screening Devices," in preparation.

Maskin, E. and J. Tirole (1990): "The Principal-Agent Relationship with an Informed Principal I: Private Values," Econometrica, 58, 379-410.

McAfee, P. (1993): "Mechanism Design by Competing Sellers," Econometrica, 61, 1281-1312.

McAfee, P. and J. McMillan, (1995), "Organizational Diseconomies of Scale", Journal of Economics and Management Strategy, 4, 399-426.

McAfee, P. and M. Schwartz (1994): "Opportunism in Multilateral Vertical Contracting: Non-Discrimination, Exclusivity and Uniformity," American Economic Review, 84, 210-230.

Melumad, N., D. Mookherjee and S. Reichelstein (1995): "Hierarchical Decentralization of Incentive Contracts," Rand Journal of Economics, 26, 654-672. 
Menezes, F., P. Monteiro and A. Temini (2001): "Private Provision of Discrete Public Goods with Incomplete Information," Journal of Mathematical Economics, 35, 493-514.

Mezzetti, C. (1997): "Common Agency with Horizontally Differentiated Principals," Rand Journal of Economics, 28, 323-345.

Milgrom, P. (2004): Putting Auction Theory to Work Cambridge: Cambridge University Press.

Mishra, A. and T. Anant (2004): "Activism, Separation of Powers and Development," Mimeo University of Dundee.

Mitra, D. (1999): "Endogenous Lobby Formation and Endogenous Protection: A Long-Run Model of Trade Policy Formation", American Economic Review, 89: 1116-1134.

Mookherjee, D., (2005): "Delegation and Contractual Hierarchies: A Mechanism Design Approach," Mimeo Boston University.

Mookherjee, D. and S. Reichelstein (2001): "Incentives and Coordination in Hierarchies," Advances in Theoretical Economics, Vol. 1, Issue 1, Article 4 .

Mookherjee, D. and M. Tsugamari (2004): "The Organization of Supplier Networks: Effects of Mergers and Intermediation," Econometrica, 72, 11791220.

Moore, J. (1992): "Implementation in Environments with Complete Information," in Advances in Economic Theory, ed. by J.J. Laffont. Cambridge: Cambridge University Press.

Myerson, R. (1979): "Incentive Compatibility and the Bargaining Problem," Econometrica, 47, 61-73.

— (1982): "Optimal Coordination Mechanisms in Generalized Principal-Agent Models," Journal of Mathematical Economics, 10, 67-81.

O'Brien, D. and G. Shaffer, (1992), "Vertical Control with Bilateral Contracts," Rand Journal of Economics, 23, 299-308.

Olsen, T. and P. Osmudsen (2001): "Strategic Tax Competition: Implications of National Ownership," Journal of Public Economics, 27, 1-31. 
- (2003): "Spillovers and International Competition for Investments," Journal of International Economics, 59, 211-238.

Olsen, T. and G. Torsvick (1993): "The Ratchet Effect in Common Agency: Implications for Regulation and Privatization," Journal of Law, Economics and Organization, 9, 136-158.

- (1995): "Intertemporal Common Agency and Organizational Design: How Much Decentralization," European Economic Review, 7, 1405-1428.

Page, F. and P. Monteiro (2003): "Three Principles of Competitive Nonlinear Pricing," Journal of Mathematical Economics, 39, 63-109.

Palfrey, T. (1992): "Implementation in Bayesian Equilibrium: The Multiple Equilibrium Problem in Mechanism Design," in Advances in Economic Theory, ed. by J.J. Laffont. Cambridge: Cambridge University Press.

Parlour, C. and U. Rajan, (2001): "Price Competition in Loan Markets," American Economic Review, 91, 1311-1328.

Pavlov, G. (2004): "Colluding on Participation Decisions," Mimeo Northwestern University.

Peck, J. (1996): "Competing Mechanisms and the Revelation Principle," Mimeo Ohio State University.

Perez-Castrillo, J. (1994): "Cooperative Outcomes through Non-Cooperative Games," Games and Economic Behavior, 7, 428-440.

Perrow, C. (1986): Complex Organizations: A critical Essay, McGraw Hill.

Peters, M. (2001): "Common Agency and the Revelation Principle," Econometrica, 69, 1349-1372.

- (2003): "Negotiation and Take-It-Or-Leave-It in Common Agency," Journal of Economic Theory, 111, 88-109.

Prat, A. and A. Rustichini (2003): "Games Played through Agents," Econometrica, 71, 989-1027.

Quesada, L. (2004): "Collusion as an Informed Principal Problem," Mimeo University of Wisconsin-Madison.

Rama, M. and G. Tabellini (1998): "Lobbying by Capital and Labor Overtrade and Labor Market Policies," European Economic Review, 42, 1296-1316. 
Rochet, J.-C. (1985): "The Taxation Principle and Multitime Hamilton-Jacobi Equations," Journal of Mathematical Economics, 14, 113-128.

Segal, I. (1999): "Contracting with Externalities," Quarterly Journal of Economics, 104, 337-388.

Segal, I. and M. Whinston (2003): "Robust Predictions for Bilateral Contracting with Externalities," Econometrica, 71, 757-792.

Stole, L. (1991): "Mechanism Design under Common Agency," Mimeo Chicago University.

- (2005): "Price Discrimination in Competitive Environments," in Handbook of Industrial Organization, eds. M. Armstrong and R. Porter, Amsterdam: North Holland.

Tirole, J. (1986): "Hierarchies and Bureaucracies : On the Role of Collusion in Organizations," Journal of Law, Economics and Organization, 2, 181-214.

- (1992): "Collusion and the Theory of Organizations," in Advances in Economic Theory: Proceedings of the Sixth World Congress of the Econometric Society, ed. J.-J. Laffont, Cambridge: Cambridge University Press.

Wilson, R. (1979), "Auctions of Shares", Quarterly Journal of Economics, 93, 675-689.

Yamashita, T. (2005): "A Unified Approach to Mechanism Design," Mimeo Stanford University. 